\title{
In Vitro Inhibition of Human Aldehyde Oxidase Activity by Clinically Relevant Concentrations of Gefitinib and Erlotinib: Comparison with Select Metabolites, Molecular Docking Analysis, and Impact on Hepatic Metabolism of Zaleplon and Methotrexate $e^{\mathbb{S}}$
}

\author{
Wee Kiat Tan, Alyssa Rui Yi Tan, Punitha Sivanandam, Ernest Jing Hui Goh, Ze Ping Yap, \\ Nur Fazilah Saburulla, Karl Austin-Muttitt, Jonathan G.L. Mullins, and Aik Jiang Lau \\ Department of Pharmacy, Faculty of Science (W.K.T., A.R.Y.T., P.S., E.J.H.G., Z.P.Y., N.F.S., A.J.L.) and Department of \\ Pharmacology, Yong Loo Lin School of Medicine (A.J.L.), National University of Singapore, Singapore, Singapore; and Institute \\ of Life Science, Swansea University Medical School, Swansea, United Kingdom (K.A.-M., J.G.L.M.)
}

Received January 19, 2020; accepted May 1, 2020

\begin{abstract}
Gefitinib and erlotinib are epidermal growth factor receptortyrosine kinase inhibitors (EGFR-TKIs) with activity against metastatic non-small cell lung cancer. Aldehyde oxidase-1 (AOX1) is a cytosolic drug-metabolizing enzyme. We conducted an experimental and molecular docking study on the effect of gefitinib, erlotinib, and select metabolites on the in vitro catalytic activity of AOX1, as assessed by carbazeran 4-oxidation, and determined the impact of AOX1 inhibition on hepatic metabolism of zaleplon and methotrexate. Gefitinib, desmorpholinopropylgefitinib, erlotinib, desmethylerlotinib, and didesmethylerlotinib inhibited human hepatic cytosolic carbazeran 4-oxidation by a competitive mode, with inhibition constants in submicromolar or low micromolar concentrations. Desmethylgefitinib did not affect AOX1 catalytic activity. A similar pattern was obtained when investigated with human kidney cytosol or recombinant AOX1. The differential effect of gefitinib on human, rat, and mouse hepatic AOX1 catalytic activity suggests speciesdependent chemical inhibition of AOX1. Erlotinib was considerably more potent than gefitinib in decreasing hepatic cytosolic zaleplon 5-oxidation and methotrexate 7-oxidation. Molecular docking analyses provided structural insights into the interaction between EGFR-TKls and AOX1, with key residues and bonds identified, which provided favorable comparison and ranking of
\end{abstract}

potential inhibitors. Based on the US Food and Drug Administration guidance to assess the risk of drug-drug interactions, the calculated $R_{1}$ values indicate that further investigations are warranted to determine whether gefitinib and erlotinib impact AOX1-mediated drug metabolism in vivo. Overall, erlotinib desmethylerlotinib, didesmethylerlotinib, gefitinib, and desmorpholinopropylgefitinib are potent inhibitors of human AOX1 catalytic function and hepatic metabolism of zaleplon and methotrexate, potentially affecting drug efficacy or toxicity.

\section{SIGNIFICANCE STATEMENT}

As epidermal growth factor receptor-tyrosine kinase inhibitors (EGFR-TKIs), gefitinib and erlotinib are first-line pharmacotherapy for metastatic non-small cell lung cancer. Our experimental findings indicate that clinically relevant concentrations of gefitinib, desmorpholinopropylgefitinib, erlotinib, desmethylerlotinib, and didesmethylerlotinib, but not desmethylgefitinib, inhibit human aldehyde oxidase (AOX1) catalytic activity and hepatic cytosolic metabolism of zaleplon and methotrexate. Molecular docking analysis provide structural insights into the key AOX1 interactions with these EGFR-TKIs. Our findings may trigger improved strategies for new EGFR-TKI design and development.

\section{Introduction}

Epidermal growth factor receptor (EGFR), which belongs to a family of receptor tyrosine kinases, is involved in cell growth, proliferation, and survival, and is overexpressed in $40 \%-80 \%$ of

This research was supported by the Singapore Ministry of Education Academic Research Fund Tier 1 [Grant R-148-000-218-112 to A.J.L.] and the Singapore Ministry of Health's National Medical Research Council under its Cooperative Basic Research Grant scheme [Grant R-148-000-225-511 to A.J.L.]. The molecular docking was undertaken using the Supercomputing Wales research facility.

https://doi.org/10.1124/jpet.120.265249.

S This article has supplemental material available at jpet.aspetjournals.org. non-small cell lung cancer (Chan and Hughes, 2015). Gefitinib and erlotinib (Supplemental Fig. 1) are first-generation EGFR tyrosine kinase inhibitors (TKIs) approved by the US Food and Drug Administration as first-line pharmacotherapy for metastatic non-small cell lung cancer in tumors with EGFR mutations (Kujtan and Subramanian, 2019). These drugs reversibly and competitively inhibit EGFR by binding to the ATP-binding site of the tyrosine kinase domain. Gefitinib undergoes oxidative metabolism catalyzed mainly by CYP2D 6 to form desmethylgefitinib (major metabolite, Supplemental Fig. 1) and by an unidentified enzyme to form desmorpholinopropylgefitinib (minor metabolite, Supplemental Fig. 1)

ABBREVIATIONS: AOX1, aldehyde oxidase-1; EGFR, epidermal growth factor receptor; $\mathrm{f}_{\mathrm{u}}$, unbound fraction; $K_{\mathrm{i}}$, inhibition constant or equilibrium dissociation constant for the enzyme-inhibitor complex; MOS, dioxothiomolybdenum (VI) ion; MS/MS, tandem mass spectrometry; TKI, tyrosine kinase inhibitor; UPLC, ultra-high-performance liquid chromatography. 
(McKillop et al., 2004; Li et al., 2007). By comparison, erlotinib is metabolized mainly by CYP3A4/CYP3A5 to form desmethylerlotinib (a major metabolite also referred to as OSI-420, Supplemental Fig. 1) and by an unidentified enzyme to form didesmethylerlotinib (minor metabolite, Supplemental Fig. 1) (Ling et al., 2006; Li et al., 2007).

Aldehyde oxidase (AOX) is a molybdenum-cofactor-containing phase I cytosolic drug-metabolizing enzyme. Multiple isoforms of this enzyme exist in rodents, including Aox1, Aox3, Aox4, and Aox3l1, but only one isoform (AOX1) in humans (Dalvie and Di, 2019). This enzyme is expressed predominantly in liver and adrenal glands and to a lesser extent in kidneys, respiratory tissue, and skin (Moriwaki et al., 2001; Nishimura and Naito, 2006; Manevski et al., 2014). AOX has a broad substrate specificity, and it is involved in the oxidation of aldehydes and nitrogen- and oxygen-containing heterocycles as well as reduction reactions (Dalvie and Di, 2019). Of particular interest in drug metabolism is the ability of AOX1 to oxidize azaheterocycles, which are common scaffolds in medicinal chemistry. Various drugs, including zaleplon (Lake et al., 2002) and methotrexate (Jordan et al., 1999), are substrates of human AOX1. Specific endogenous substances have also been identified as AOX substrates, as reported in animal studies showing retinaldehyde metabolism catalyzed by rabbit AOX (Tomita et al., 1993), whereas N1-methylnicotinamide (Stanulović and Chaykin, 1971) and pyridoxal (Stanulović and Chaykin, 1971) metabolism are catalyzed by mouse Aox, and $\mathrm{M}_{1} \mathrm{dG}$ DNA adduct (Otteneder et al., 2006; Wauchope et al., 2015) and NADH (Kundu et al., 2012) metabolism are catalyzed by rat Aox. Studies are also emerging to investigate the role of AOX in adipogenesis and locomotor activity (Qiao et al., 2020).

Previous studies reported that certain drug classes, such as selective estrogen receptor modulators, are capable of inhibiting the in vitro catalytic activity of human AOX1 (Obach, 2004; Obach et al., 2004; Chen et al., 2019). Whether EGFR-TKIs as a drug class are chemical inhibitors of AOX1 is not known, but as shown in Supplemental Figs. 1 and 2, common chemical structural features exist between both EGFR-TKIs and several known lipophilic, azaheterocycle-containing AOX1 substrates, such as carbazeran, zaleplon, and methotrexate. As part of an overall aim to identify chemical inhibitors of AOX with potential clinical relevance, experiments in this study were designed to: 1) determine the inhibitory potential of erlotinib, gefitinib, and select metabolites on human AOX1 catalytic activity, as assessed by carbazeran 4-oxidation, an AOX1selective catalytic marker (Xie et al., 2019); 2) characterize the enzyme kinetics of AOX1 inhibition by these EGFR-TKIs; 3) conduct molecular docking analysis to elucidate the mechanisms by which EGFR-TKIs compete directly with AOX1 substrates to inhibit the catalytic activity of AOX1; and 4) evaluate the impact of AOX1 inhibition on hepatic cytosolic metabolism of clinically prescribed therapeutic agents (i.e., zaleplon and methotrexate) known to be AOX1 substrates. The results of this study highlight the potent inhibition of AOX1 catalytic function and hepatic cytosolic drug metabolism by clinically relevant concentrations of erlotinib and gefitinib.

\section{Materials and Methods}

Chemicals, Reagents, and Enzymes. Desmethylgefitinib, desmorpholinopropylgefitinib, erlotinib, desmethylerlotinib, didesmethylerlotinib, carbazeran, 4-oxo-carbazeran (4-hydroxycarbazeran), zaleplon, 5-oxo-zaleplon, methotrexate, and 7-oxo-methotrexate (7-hydroxymethotrexate) were purchased from Toronto Research Chemicals, Inc. (North York, ON, Canada). Raloxifene, hydralazine, sodium valproate, tolbutamide, and DMSO were purchased from Sigma-Aldrich Corp. (St. Louis, MO). Gefitinib and methotrexate were bought from Cayman Chemicals (Ann Arbor, MI). All other commercially available chemicals were of analytical or high-performance liquid chromatographic grade. The details of human liver, human kidney, rat liver, and mouse liver cytosols used in this study are described in Supplemental Table 1. Human recombinant AOX1 enzyme (catalog CYP150, lot 150011B) and control cytosol (isolated from Escherichia coli host cells; catalog CYP099, lot INT016E18C) were purchased from Cypex Ltd. (Dundee, Scotland, UK).

Carbazeran 4-Oxidation Assay. Carbazeran 4-oxidation assay was conducted as described in our previous study (Chen et al., 2019), except that the final concentration of DMSO in all samples was $0.5 \% \mathrm{v} /$ $\mathrm{v}$, which was shown not to affect the catalytic activity of AOX1 (Behera et al., 2014).

Zaleplon 5-Oxidation Assay. Each incubation mixture $(200 \mu \mathrm{l})$ contained potassium phosphate buffer (100 mM, pH 7.4), zaleplon (80 $\mu \mathrm{M}$ ), and human liver cytosol (60 $\mu \mathrm{g}, 0.3 \mathrm{mg} / \mathrm{ml}$ final concentration), unless otherwise specified in the figure legend. The mixture was prewarmed for 3 minutes at $37^{\circ} \mathrm{C}$ in a shaking water bath. Enzymatic reaction was initiated by adding liver cytosol and the mixture was incubated for 20 minutes. The reaction was terminated by adding an equal volume $(200 \mu \mathrm{l})$ of ice-cold acetonitrile containing tolbutamide (25 nM final concentration; internal standard). Each sample was mixed, placed immediately in an ice bath, and centrifuged at $16,000 \mathrm{~g}$ for 15 minutes at $4^{\circ} \mathrm{C}$. The supernatant was transferred to a 96 -well microplate for analysis of 5-oxo-zaleplon and tolbutamide by ultrahigh-performance liquid chromatography (UPLC)-tandem mass spectrometry (MS/MS).

Methotrexate 7-Oxidation Assay. Each incubation mixture $(200 \mu \mathrm{l})$ contained potassium phosphate buffer (100 mM, pH 7.4), methotrexate $(1.5 \mathrm{mM})$, and human liver cytosol $(100 \mu \mathrm{g}, 0.5 \mathrm{mg} / \mathrm{ml}$ final concentration), unless otherwise specified in the figure legend. The mixture was prewarmed for 3 minutes at $37^{\circ} \mathrm{C}$ in a shaking water bath. Enzymatic reaction was initiated by adding liver cytosol, and the mixture was incubated for 180 minutes. The reaction was terminated by adding an equal volume $(200 \mu \mathrm{l})$ of ice-cold acetonitrile containing tolbutamide (25 nM final concentration; internal standard). Each sample was mixed, placed immediately in an ice bath, and centrifuged at $16,000 \mathrm{~g}$ for 15 minutes at $4^{\circ} \mathrm{C}$. The supernatant was transferred to a 96-well microplate for analysis of 7-oxo-methotrexate and tolbutamide by UPLC-MS/MS.

Quantification of 4-Oxo-Carbazeran, 5-Oxo-Zaleplon, and 7-Oxo-Methotrexate by UPLC-MS/MS. The UPLC-MS/MS system and the chromatographic and mass spectrometric conditions for analyzing 4-oxo-carbazeran and tolbutamide (internal standard) were described in detail in our previous study (Xie et al., 2019). The amount of 5-oxo-zaleplon and 7-oxo-methotrexate was quantified by using an Agilent 1290 Infinity LC system (Agilent Technologies, Santa Clara, CA) coupled with a triple quadrupole mass spectrometer (AB SCIEX Triple Quad 3500 LC/MS/MS system with a Turbo V ion source; AB Sciex LLC, Framingham, MA) and interfaced with the Analyst software, version 1.6.2 (AB Sciex LLC). Chromatographic separation was carried out by using a Waters ACQUITY UPLC BEH $\mathrm{C}_{18}$ VanGuard precolumn, $2.1 \times 5 \mathrm{~mm}$ i.d., $1.7 \mu \mathrm{m}$, and a Waters ACQUITY UPLC BEH C 18 column, $2.1 \times 50 \mathrm{~mm}$ i.d., $1.7 \mu \mathrm{m}$ (Waters Corporation, Milford, MA). MultiQuant software version 3.0.1 (AB Sciex LLC) was used to integrate the chromatographic peaks and quantify the analytes in each sample.

The autosampler temperature and column temperature were maintained at $4^{\circ} \mathrm{C}$ and $45^{\circ} \mathrm{C}$, respectively. The solvent flow rate was $0.5 \mathrm{ml} / \mathrm{min}$, and the sample injection volume was $5 \mu \mathrm{l}$. The mobile phase consisted of (A) $0.1 \% \mathrm{v} / \mathrm{v}$ formic acid in water and (B) $0.1 \% \mathrm{v} / \mathrm{v}$ formic acid in acetonitrile. In the analysis of 5-oxo-zaleplon and zaleplon, the optimized elution conditions were as follows: isocratic 
A Human Recombinant AOX1 B Human Recombinant AOX1 C Human Recombinant AOX1
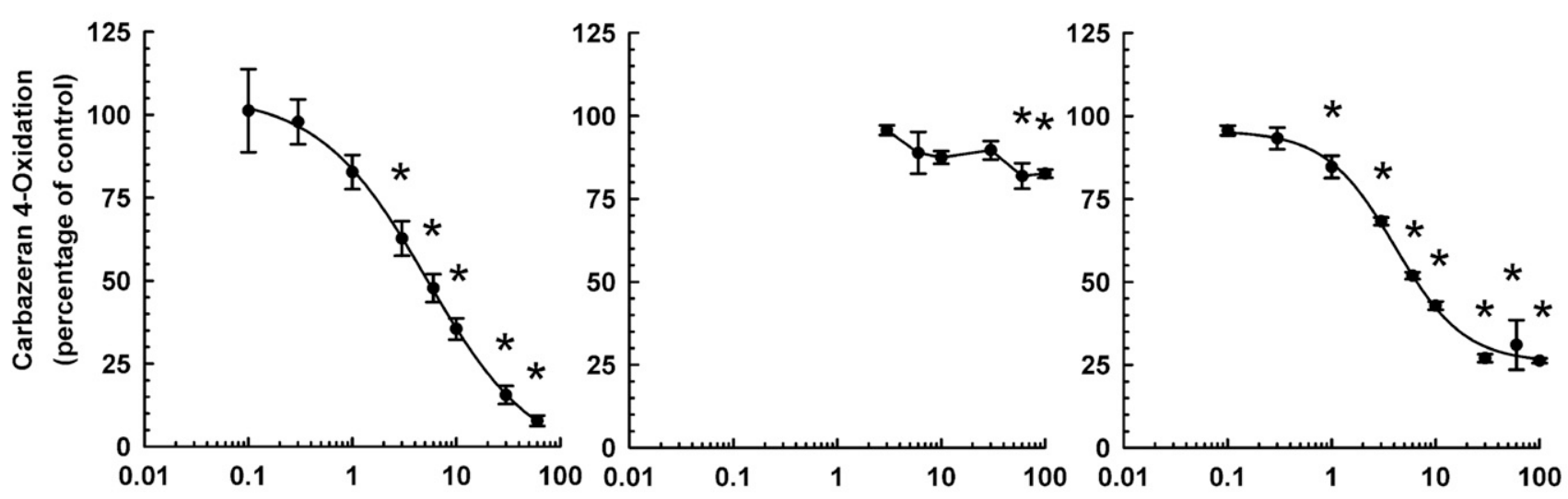

D Human Liver Cytosol

E Human Liver Cytosol

F Human Liver Cytosol
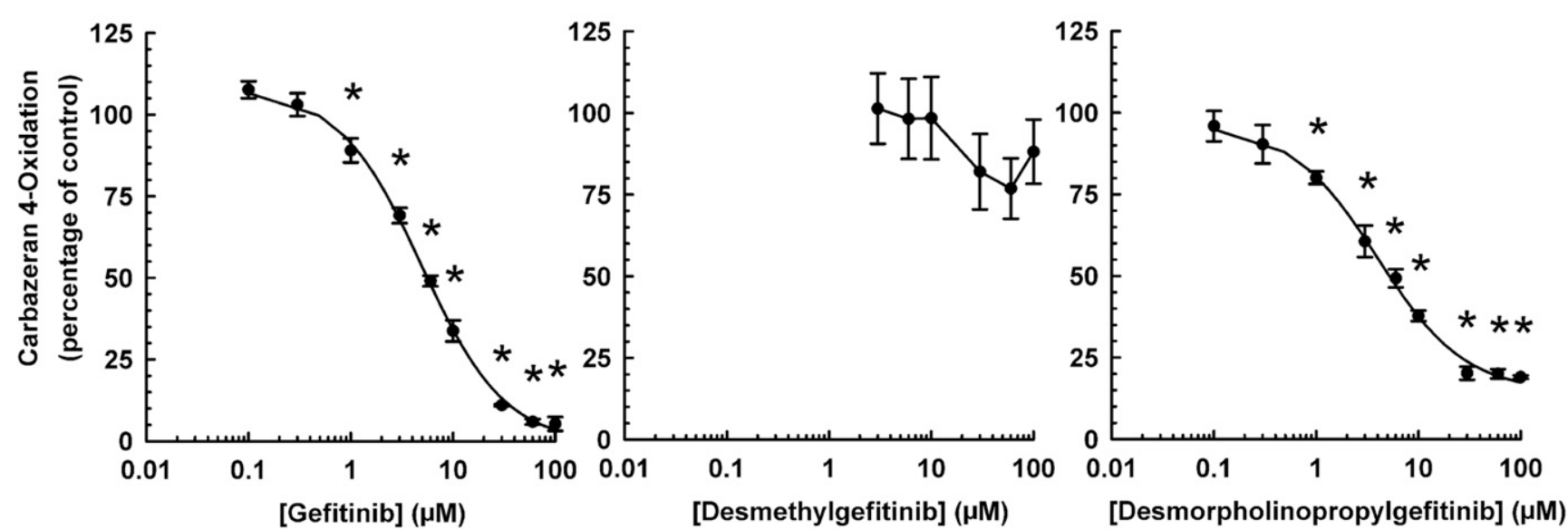

Fig. 1. Concentration-response relationship in the inhibitory effect of gefitinib, desmethylgefitinib, and desmorpholinopropylgefitinib on carbazeran 4-oxidation catalyzed by human recombinant AOX1 and liver cytosol. Recombinant AOX1 (30 $\mu \mathrm{g}$ protein) or pooled liver cytosol (20 $\mu \mathrm{g}$ protein) was incubated with carbazeran $(5 \mu \mathrm{M})$ and varying concentrations of (A and D) gefitinib $(0.1-60 \mu \mathrm{M}$ for recombinant AOX1; $0.1-100 \mu \mathrm{M}$ for liver cytosol), (B and E) desmethylgefitinib (3-100 $\mu \mathrm{M}),\left(\mathrm{C}\right.$ and F) desmorpholinopropylgefitinib $(0.1-100 \mu \mathrm{M})$, or DMSO $\left(0.5 \%\right.$ v/v; vehicle) at $37^{\circ} \mathrm{C}$ for 15 minutes (recombinant AOX1) or 5 minutes (liver cytosol). Data are expressed as percentage of activity in the vehicle-treated control group and expressed as mean \pm S.E.M. of three or four independent experiments conducted in duplicate or triplicate. *Significantly different from the vehicle-treated control group $(P<0.05)$.

at $5 \% \mathrm{~B}$ from 0 to 1 minute, linear increase from $5 \%$ to $95 \% \mathrm{~B}$ from 1.0 to 2.0 minutes, isocratic at $95 \% \mathrm{~B}$ from 2.0 to 3.5 minutes, linear decrease from $95 \%$ to $5 \%$ B from 3.5 to 3.6 minutes, and isocratic at $5 \% \mathrm{~B}$ from 3.6 to 4.5 minutes. In the analysis of 7-oxo-methotrexate and methotrexate, a stepwise elution was used as follows: isocratic at $5 \%$ B from 0 to 1 minute, $5 \%-20 \%$ B from 1.0 to 1.5 minutes, $20 \% \mathrm{~B}$ from 1.5 to 2.5 minutes, $20 \%-95 \%$ B from 2.5 to 2.6 minutes, $95 \% \mathrm{~B}$ from 2.6 to 3.5 minutes, $95 \%-5 \%$ B from 3.51 to 3.6 minutes, and isocratic at $5 \% \mathrm{~B}$ from 3.6 to 4.5 minutes. The chromatographic eluate was diverted into the mass spectrometer from 1.4 to 3.5 minutes (for 7oxo-methotrexate) and 1.5 to 3.5 minutes (for 4-oxo-carbazeran and 5oxo-zaleplon). The analytes were detected in the positive electrospray ionization mode. Each analyte was monitored by using two multiplereaction monitoring transitions. The mass-to-charge transitions, compound-dependent mass spectrometry parameters, and ion source parameters are shown in Supplemental Table 2.

The preparation of the standard curve for 4-oxo-carbazeran and validation of the method were described in our previous study (Xie et al., 2019). To construct a calibration curve for each experiment, 5oxo-zaleplon (3-10,000 $\mu \mathrm{M}$ in DMSO) or 7-oxo-methotrexate (5-3000 $\mu \mathrm{M}$ in DMSO) stock solutions were freshly added to the incubation mixture to give final concentrations of $3-10,000 \mathrm{nM}(0.6-2000 \mathrm{pmol}$ in $0.1 \% \mathrm{v} / \mathrm{v}$ DMSO) or $5-3000 \mathrm{nM}(1-600 \mathrm{pmol}$ in $0.1 \% \mathrm{v} / \mathrm{v} \mathrm{DMSO})$, respectively. Lower limit of quantification and quality control samples were prepared by adding a known amount of metabolite standard $(0.6,1.5,30$, or 300 pmol 5-oxo-zaleplon; $1,3,30$, or 300 pmol 7-oxomethotrexate) into the incubation mixture. Both standard and quality control samples were subjected to the same procedures as described under Zaleplon 5-Oxidation Assay or Methotrexate 7-Oxidation Assay. Matrix effect was evaluated by analyzing low-, mid-, and high-quality control samples in the absence or presence of enzymes (60 $\mu \mathrm{g}$ for 5-oxozaleplon and $100 \mu \mathrm{g}$ for 7-oxo-methotrexate). A calibration curve was constructed by using weighted $\left(1 / \mathrm{x}^{2}\right)$ linear least-squares regression analysis of the peak area ratio (analyte to internal standard) versus amount of the metabolite standard added into the incubation mixture. The amount of 7-oxo-methotrexate quantified in a blank sample containing methotrexate only was subtracted from the amount of 7-oxo-methotrexate quantified in each sample to calculate the net amount of 7-oxo-methotrexate formed by the enzymatic reaction.

Enzyme Kinetics and Enzyme Inhibition Experiments. Enzyme kinetic experiment was performed as described previously (Chen et al., 2019). The intrinsic clearance was calcuated by dividing $V_{\max }$ by Michaelis-Menten constant. Enzyme inhibition was determined by conducting the assays in the presence of an inhibitor or the vehicle $(0.5 \% \mathrm{v} / \mathrm{v} \mathrm{DMSO})$ at concentrations specified in each figure legend. In the concentration-response experiment, the half-maximal inhibitory 

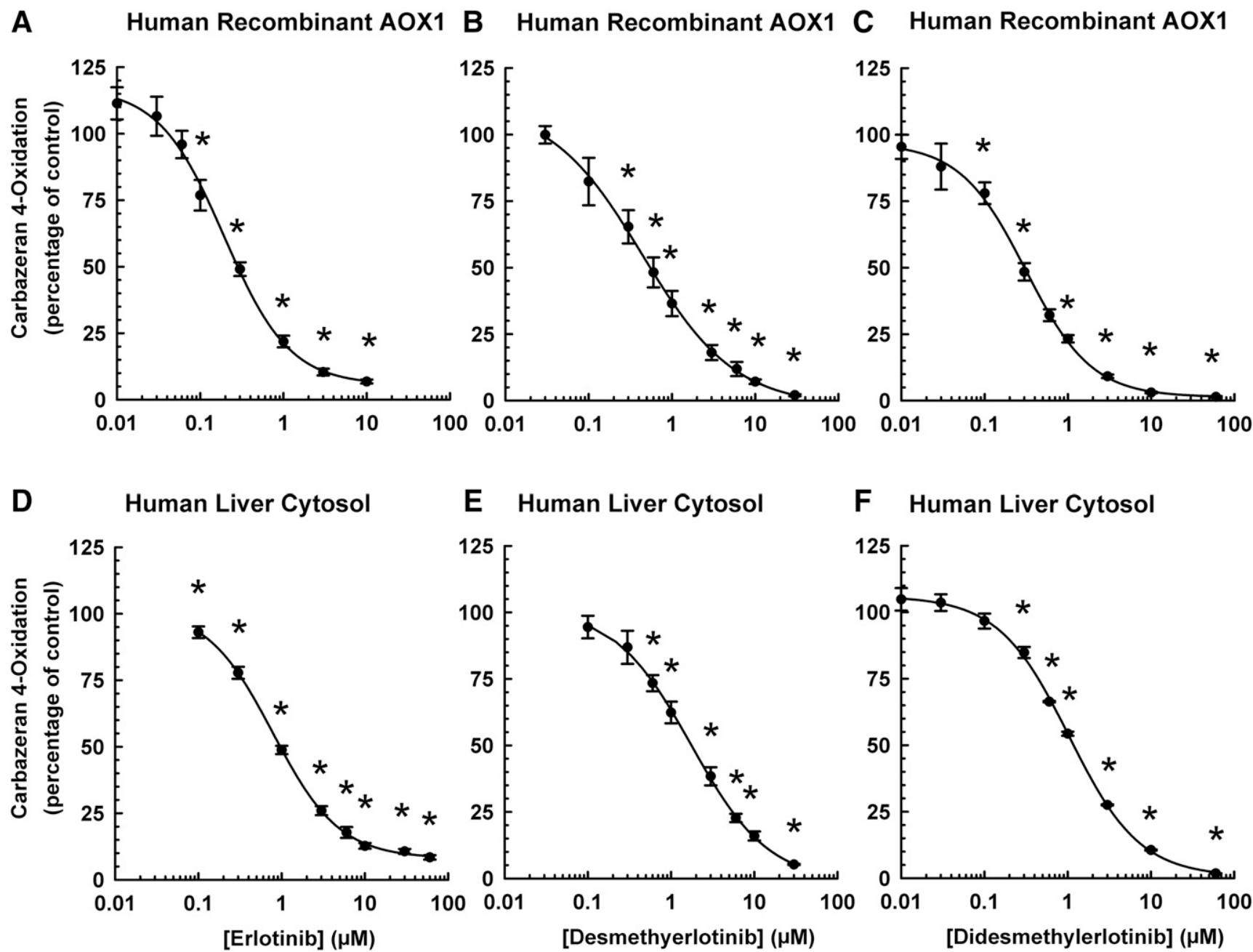

Fig. 2. Concentration-response relationship in the inhibitory effect of erlotinib, desmethylerlotinib, and didesmethylerlotinib on carbazeran 4-oxidation catalyzed by human recombinant AOX1 and liver cytosol. Recombinant AOX1 (30 $\mu \mathrm{g}$ protein) or pooled liver cytosol ( $20 \mu \mathrm{g}$ protein) was incubated with carbazeran $(5 \mu \mathrm{M})$ and varying concentrations of (A and D) erlotinib (0.01-10 $\mu \mathrm{M}$ for recombinant AOX1; 0.1-60 $\mu \mathrm{M}$ for liver cytosol), (B and E) desmethylerlotinib (0.03-30 $\mu \mathrm{M}$ for recombinant AOX1; 0.1-30 $\mu \mathrm{M}$ for liver cytosol), (C and F) didesmethylerlotinib (0.01-60 $\mu \mathrm{M})$, or DMSO (0.5\% v/v; vehicle) at $37^{\circ} \mathrm{C}$ for 15 minutes (recombinant AOX1) or 5 minutes (liver cytosol). Data are expressed as percentage of activity in the vehicle-treated control group and expressed as mean \pm S.E.M. of three independent experiments conducted in duplicate or triplicate. *Significantly different from the vehicle-treated control group $(P<0.05)$.

concentration $\left(\mathrm{IC}_{50}\right)$ value was determined by curve-fitting the experimental data to the following equation (Sigmaplot 12.5):

$$
\text { Effect }=E_{0}+\frac{E_{\max }-E_{0}}{1+\left(x / I C_{50}\right)^{- \text {Hillslope }}}
$$

where $x$ is the inhibitor concentration, $E_{0}$ is the minimum effect, $E_{\max }$ is the maximum effect, and Hillslope is the Hill coefficient.

To determine the enzyme kinetics of AOX1 inhibition by EGFRTKIs, the carbazeran 4-oxidation and zaleplon 5-oxidation assays were conducted in the presence of multiple concentrations of carbazeran $(0.5,2,5,10$, or $20 \mu \mathrm{M})$ or zaleplon $(20,40,60$, or $80 \mu \mathrm{M})$ and multiple concentrations of an EGFR-TKI, as specified in the figure legend. The $K_{\mathrm{i}}$ (equilibrium dissociation constant for the enzymeinhibitor complex) value and mode of inhibition were determined by nonlinear least-squares regression analysis of the metabolite formation data at various concentrations of the inhibitor and substrate, using equations for full and partial competitive, noncompetitive, uncompetitive, and mixed-mode inhibition (Sigmaplot 12.5). The best-fit model was determined by the corrected Akaike information criterion, $R^{2}$, S.D. of the residuals, and visual inspection of the data in the Lineweaver-Burk and Dixon plots. The equations for the full competitive inhibition model (eq. 1) and the partial competitive inhibition model (eq. 2) are as follows:

$$
\begin{gathered}
v=\frac{V \max }{1+(K m / S) *(1+\mathrm{I} / \mathrm{Ki})} \\
v=\frac{V \max }{1+\left(\frac{K m}{S}\right) * \frac{1+\frac{1}{\mathrm{Ki}}}{1+\frac{1}{\alpha^{*} \mathrm{Ki}}}}
\end{gathered}
$$

where $S$ represents the substrate concentration, $I$ represents the inhibitor concentration, $V_{\max }$ represents the maximum reaction velocity, $K_{\mathrm{m}}$ represents the substrate concentration at which the reaction rate is half of $V_{\max }$, and $K_{\mathrm{i}}$ represents the equilibrium dissociation constant for the enzyme-inhibitor complex.

Rapid Equilibrium Dialysis and Determination of the Unbound Fraction. Nonspecific binding of test chemicals to human liver cytosol was determined by using a Rapid Equilibrium Dialysis Kit (Thermo Fisher Scientific, Waltham, MA), as described in detail in our previous publication (Xie et al., 2019). Briefly, a mixture (total volume of $200 \mu \mathrm{l})$ containing potassium phosphate buffer $(100 \mathrm{mM}, \mathrm{pH}$ 7.4), a test chemical ( 1 or $10 \mu \mathrm{M}$ in a final concentration of $0.5 \% \mathrm{v} / \mathrm{v}$ DMSO), and human liver cytosol (20 $\mu \mathrm{g}$ total cytosolic protein) was 
TABLE 1

Enzyme kinetic analysis of the inhibition of human liver cytosolic AOX1-mediated carbazeran 4-oxidation and zaleplon 5-oxidation by gefitinib, erlotinib, and select metabolites

Data are expressed as mean \pm S.E.M. for three independent experiments conducted in duplicate.

\begin{tabular}{|c|c|c|c|c|}
\hline \multirow[b]{2}{*}{ Chemical } & \multicolumn{2}{|c|}{$\begin{array}{l}\text { Carbazeran } \\
\text { 4-Oxidation }\end{array}$} & \multicolumn{2}{|c|}{$\begin{array}{l}\text { Zaleplon } \\
\text { 5-Oxidation }\end{array}$} \\
\hline & $K_{\mathrm{i}}, \mu \mathrm{M}$ & Mode of Inhibition & $K_{\mathrm{i}}, \mu \mathrm{M}$ & Mode of Inhibition \\
\hline Gefitinib & $1.74 \pm 0.39$ & Competitive (Full) & $3.24 \pm 0.38$ & Competitive (Full) \\
\hline Desmethylgefitinib & n.d. & n.d. & n.d. & n.d. \\
\hline Desmorpholinopropylgefitinib & $1.58 \pm 0.11$ & Competitive (Partial) & $7.64 \pm 1.67^{a}$ & Competitive (Full) \\
\hline Erlotinib & $0.26 \pm 0.02$ & Competitive (Partial) & $0.10 \pm 0.01$ & Competitive (Full) \\
\hline Desmethylerlotinib & $0.51 \pm 0.05^{a}$ & Competitive (Full) & $0.22 \pm 0.03^{a}$ & Competitive (Full) \\
\hline Didesmethylerlotinib & $0.28 \pm 0.01$ & Competitive (Full) & $0.11 \pm 0.01$ & Competitive (Full) \\
\hline
\end{tabular}

n.d., not determined because there was no clear concentration-dependent decrease in activity.

${ }^{a}$ Significantly different from the parent drug group $(P<0.05)$.

added to the sample chamber of the dialysis plate, whereas potassium phosphate buffer was added to the buffer chamber. The dialysis was conducted at $37^{\circ} \mathrm{C}$ for 4 hours on an incubator/mixer (ThermoMixer C; Eppendorf AG, Hamburg, Germany) set at an orbital rotating speed of $300 \mathrm{rpm}$. At the end of the incubation period, a $25-\mu \mathrm{l}$ aliquot of the incubation mixture from each of the buffer and the sample chamber was transferred into a microcentrifuge tube and mixed with $475 \mu \mathrm{l}$ of ice-cold acetonitrile containing $5 \mathrm{nM}$ erlotinib (internal standard for analysis of gefitinib and its metabolites; final concentration of $4.75 \mathrm{nM}$ in $500 \mu$ l final volume) or $200 \mathrm{nM}$ gefitinib (internal standard for analysis of erlotinib and its metabolites; final concentration of $190 \mathrm{nM}$ in $500 \mu$ l final volume). The unbound fraction $\left(f_{u}\right)$ of a chemical was calculated as the ratio of the chemical concentration in the buffer chamber to that in the sample chamber.
A Gefitinib

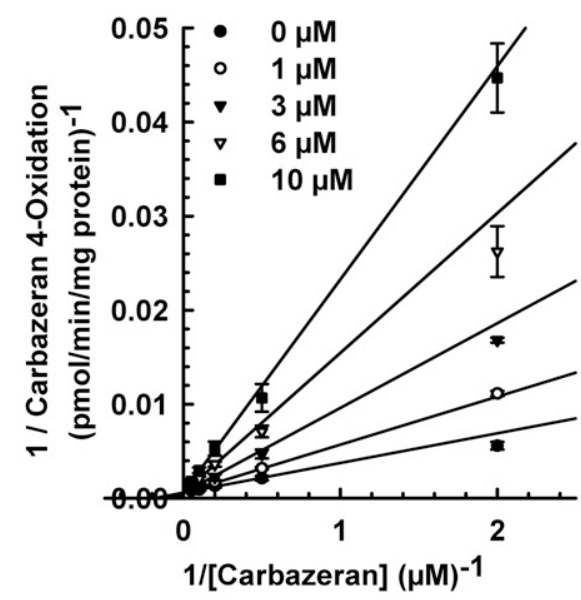

D Desmethylerlotinib

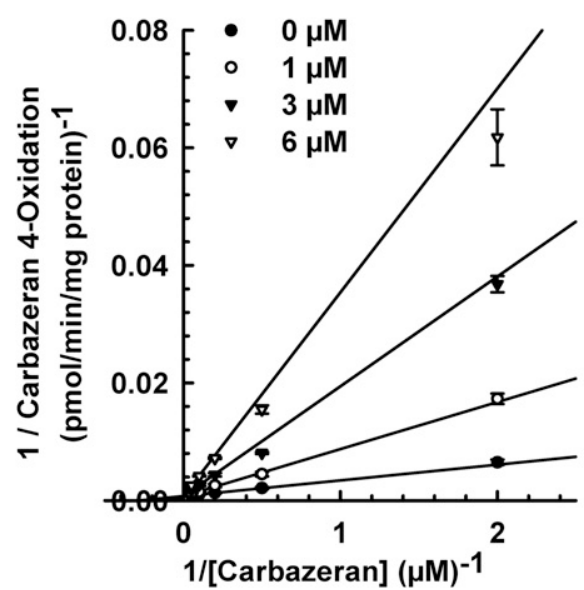

B Desmorpholinopropylgefitinib

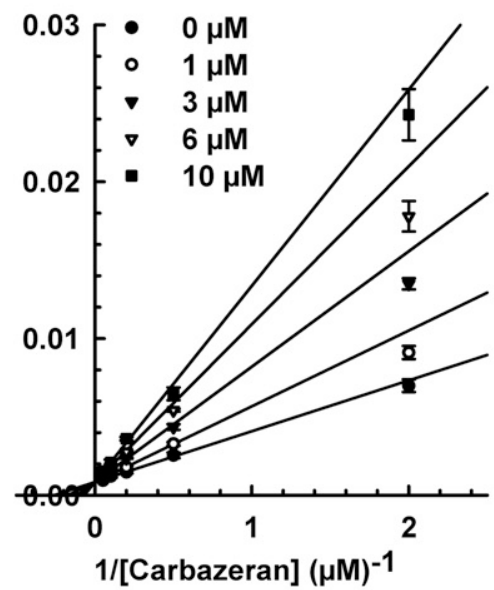

E Didesmethylerlotinib

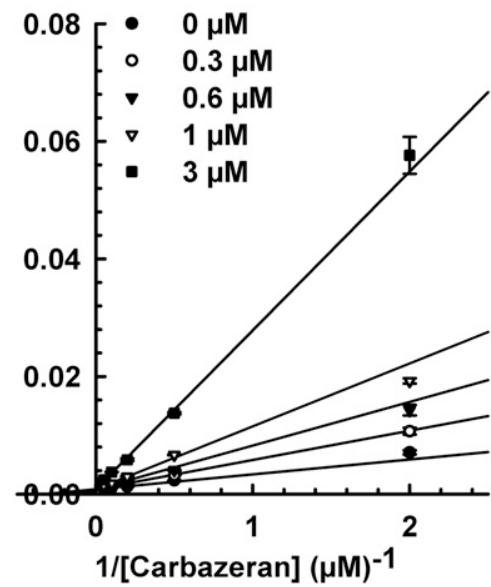

C Erlotinib

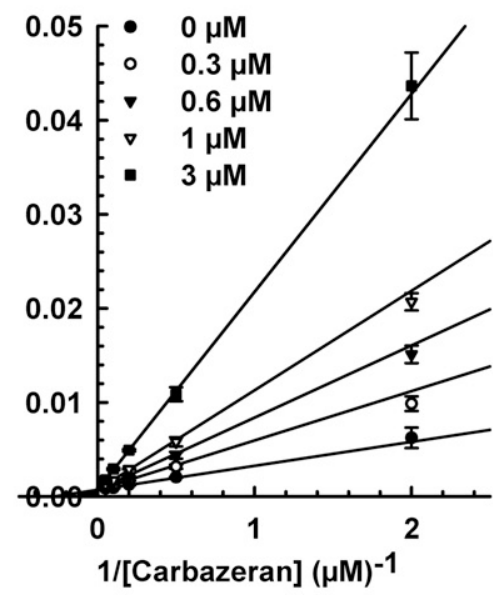

Fig. 3. Lineweaver-Burk plots for inhibition of human liver cytosolic AOX1-mediated carbazeran 4-oxidation by gefitinib, erlotinib, and select metabolites. Pooled liver cytosol (20 $\mu \mathrm{g}$ protein) was incubated with carbazeran $(0.5,2,5,10$, or $20 \mu \mathrm{M})$ and varying concentrations of (A) gefitinib (0, 1,3 , 6 , or $10 \mu \mathrm{M})$, (B) desmorpholinopropylgefitinib $(0,1,3,6$, or $10 \mu \mathrm{M})$, (C) erlotinib $(0,0.3,0.6,1$, or $3 \mu \mathrm{M})$, (D) desmethylerlotinib (0, 1, 3, or $6 \mu \mathrm{M})$, (E) didesmethylerlotinib $(0,0.3,0.6,1$, or $3 \mu \mathrm{M})$, or DMSO $\left(0.5 \% \mathrm{v} / \mathrm{v}\right.$; vehicle) at $37^{\circ} \mathrm{C}$ for 5 minutes. Data are expressed as mean \pm S.E.M. reciprocal metabolite formation of three independent experiments conducted in duplicate. *Significantly different from the vehicle-treated control group $(P<0.05)$. 
A

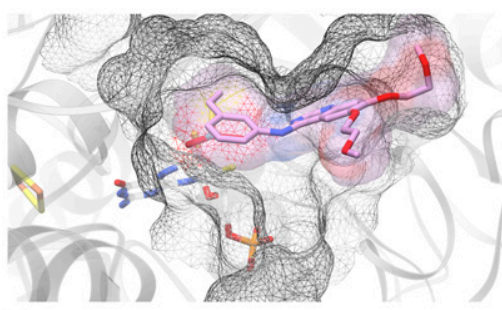

C

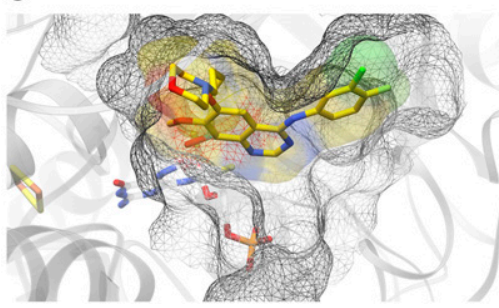

B

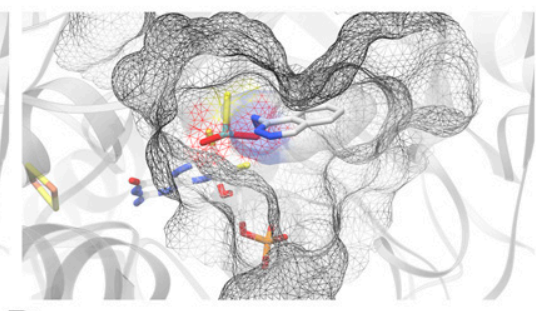

D

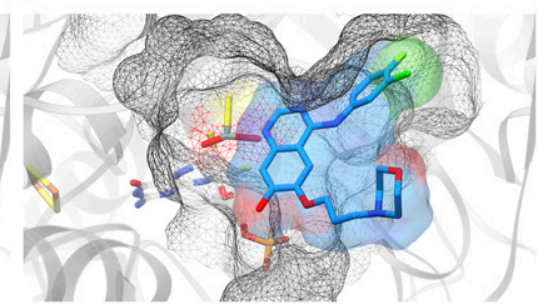

Fig. 4. Molecular docking of compounds to the active site of human AOX1. The predicted binding of the compounds is shown with the molybdenum cofactor MOS visible toward the center of each frame. The key amino acid residues are shown. (A) Molecular docking of erlotinib in the active pocket of AOX1. Desmethylerlotinib and didesmethylerlotinib bind in a similar overall orientation. (B) Docking of hydralazine to AOX1 occurred at a greater distance from the molybdenum cofactor than erlotinib and with fewer interactions with surrounding residues. (C) Docking of gefitinib to AOX1. Desmorpholinopropylgefitinib binds similarly to AOX1. (D) Desmethylgefitinib binds at the entrance of the pocket, and extrudes out from it, rather than gaining full access to the active site.
Quantification of Gefitinib, Erlotinib, and Select Metabolites by UPLC-MS/MS. These drugs and metabolites were quantified by a UPLC-MS/MS system, as described under Quantification of 4-Oxo-Carbazeran, 5-Oxo-Zaleplon, and 7-Oxo-Methotrexate by UPLC-MS / MS. The calibration standards consisted of a combined mixture of gefitinib, desmethylgefitinib, and desmorpholinopropylgefitinib or a combined mixture of erlotinib, desmethylerlotinib, and didesmethylerlotinib with final concentrations of $0.01-10 \mu \mathrm{M}$ in $0.1 \%$ DMSO in the incubation mixture. Ice-cold acetonitrile $(475 \mu \mathrm{l})$ containing an appropriate internal standard (final concentration of $4.75 \mathrm{nM}$ erlotinib or $190 \mathrm{nM}$ gefitinib in $500 \mu \mathrm{l}$ solution) was added to $25 \mu \mathrm{l}$ of the standard mixture, similar to that described for the samples above. The autosampler temperature and column temperature were maintained at $4^{\circ} \mathrm{C}$ and $45^{\circ} \mathrm{C}$, respectively. The solvent flow rate was $0.5 \mathrm{ml} / \mathrm{min}$, and the sample injection volume was $5 \mu \mathrm{l}$. The mobile phase consisted of (A) $0.1 \% \mathrm{v} / \mathrm{v}$ formic acid in water and (B) $0.1 \% \mathrm{v} / \mathrm{v}$ formic acid in acetonitrile. In the analysis of gefitinib, desmethylgefitinib, and desmorpholinopropylgefitinib, the optimized elution conditions were as follows: isocratic at $5 \% \mathrm{~B}$ from 0 to 1 minute, $5 \%-95 \% \mathrm{~B}$ from 1.0 to 2.0 minutes, isocratic at $95 \% \mathrm{~B}$ from 2.0 to 3.5 minutes, $95 \%-5 \%$ B from 3.5 to 3.6 minutes, and isocratic at $5 \%$ B from 3.6 to 4.5 minutes. In the analysis of erlotinib, desmethylerlotinib, and didesmethylerlotinib, the optimized elution conditions were as follows: isocratic at $5 \% \mathrm{~B}$ from 0 to 1 minute, $5 \%-80 \% \mathrm{~B}$ from 1.0 to 2.0 minutes, isocratic at $80 \% \mathrm{~B}$ from 2.0 to 3.5 minutes, $80 \%-5 \%$ B from 3.5 to 3.6 minutes, and isocratic at $5 \% \mathrm{~B}$ from 3.6 to 4.5 minutes. The chromatographic eluate was diverted into the mass spectrometer from 1.5 to 3.5 minutes. The analytes were detected in the positive electrospray ionization mode. Each analyte was monitored by using two multiple-reaction monitoring transitions. The mass-to-charge transitions, compound-dependent mass spectrometry parameters, and ion source parameters are shown in Supplemental Table 3.

Molecular Docking. We used the molecular docking methodology described in our previous study (Chen et al., 2019). An initial exploratory docking study was conducted from which a cluster sample of conformation ( 60 for the erlotinib family, 30 in the gefitinib family) were reviewed manually. The initial study generated poses for erlotinib that were oriented similarly to the urate ligand in xanthine oxidoreductase (Protein Data Bank \#3AMZ) (Okamoto et al., 2010).

Statistical Analysis. Data were analyzed by one-way or two-way analysis of variance and, where appropriate, followed by the StudentNewman-Keuls multiple comparison test (SigmaPlot 12.5). Data obtained from experiments with two groups were analyzed by the Student's $t$ test (one-tail). The level of statistical significance was set a priori at $P<0.05$.

TABLE 2

Molecular docking analysis of human AOX1 and inhibitors

$\mathrm{IC}_{50}$ values were determined as described under Materials and Methods.

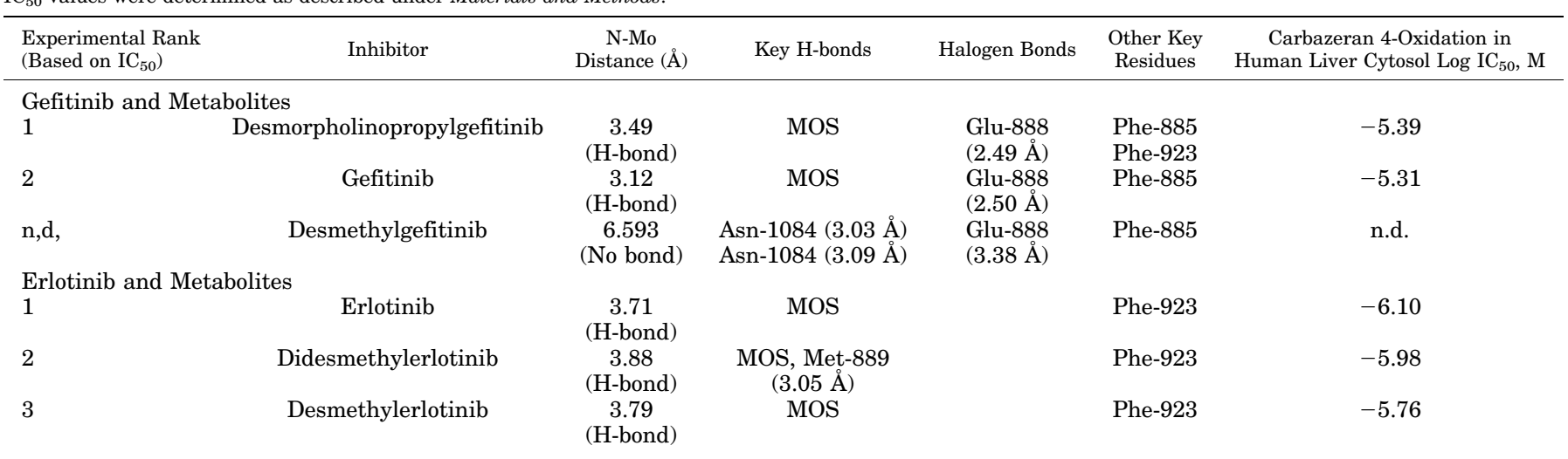

n.d., not determined. 
A

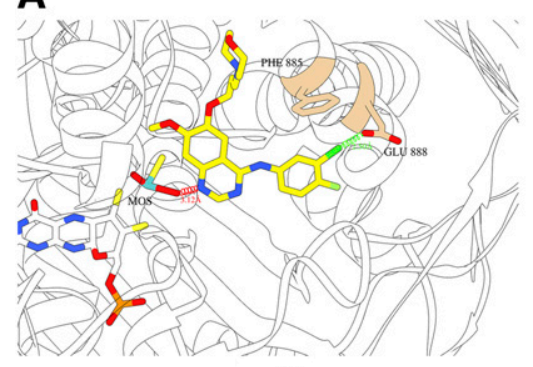

B

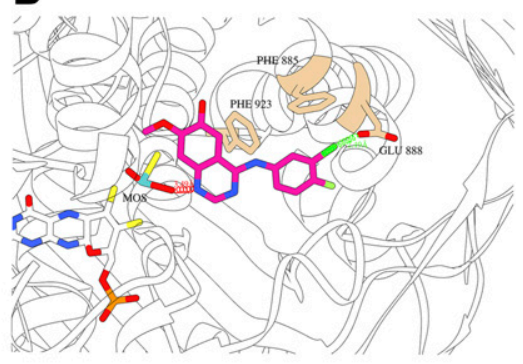

Fig. 5. (A) Key interactions of gefitinib with human AOX1. The larger morpholinopropyl side chain affects the orientation of the ligand slightly, creating a stronger $\mathrm{H}$-bond to MOS but drawing it away from Phe-923. (B) Key interactions of desmorpholinopropylgefitinib with human AOX1. Phe- 885 and Phe-923 are proximal to the halogenated ring, and the ligand chlorine forms a halogen-bond to Glu-888. The central ring forms a H-bond to MOS. (C) Key interactions of the inactive desmethylgefitinib with human AOX1. The halogenated ring enters the Phe-885/Glu-888 subpocket and maintains interactions with those two residues. However, the double-ring system (quinazoline ring) has a newly exposed $\mathrm{H}$-bond donor because the $\mathrm{C}_{7}$ $O$-methyl group group is truncated to a hydroxyl, allowing it to form an H-bond to the carbonyl group in Asn-1084. In this orientation, the asparagine amine can in turn form an $\mathrm{H}$-bond to the remaining $\mathrm{C}_{6}$ ether group in the morpholinopropyl side chain of the ligand. This very tight bond to Asn-1084 prevents the ligand from moving into the molybdenum chamber.

\section{Results}

Effect of Gefitinib, Erlotinib, and Select Metabolites on AOX1 Catalytic Activity. Carbazeran 4-oxidation is an enzyme-selective catalytic marker of AOX1 (Xie et al., 2019). Therefore, optimization experiments were conducted to identify the linear range of the carbazeran 4-oxidation assay with respect to the amount of cytosolic protein (Supplemental Fig. 3, A-F) and incubation time (Supplemental Fig. 4, A-F). Carbazeran 4-oxidation catalyzed by human, rat, and mouse liver cytosol preparations was best described by the MichaelisMenten model (Supplemental Fig. 5, A-F). The enzyme kinetic constants are summarized in Supplemental Table 5. The assay conditions for human recombinant AOX1-catalyzed carbazeran 4-oxidation were optimized previously (Chen et al., 2019).

Gefitinib and desmorpholinopropylgefitinib, but not desmethylgefitinib, decreased human recombinant AOX1-catalyzed carbazeran 4-oxidation (Fig. 1, A-C; Supplemental Fig. 6A). By comparison, erlotinib, desmethylerlotinib, and didesmethylerlotinib were equally effective in inhibiting recombinant AOX1 catalytic activity (Fig. 2, A-C; Supplemental Fig. 6A). A similar pattern was observed for the inhibition of AOX1 catalytic activity in human liver cytosol and human kidney cytosol by gefitinib, desmorpholinopropylgefitinib, erlotinib, desmethylerlotinib, and didesmethylerlotinib (Figs. 1, D-F and 2, D-F; Supplemental Fig. 6, B and C). A comparison of experimentally derived $\mathrm{IC}_{50}$ values indicated that erlotinib, desmethylerlotinib, and didesmethylerlotinib were more potent than gefitinib and desmorpholinopropylgefitinib in the inhibition of human liver cytosolic AOX1 activity (Supplemental Table 6). The negative control, sodium valproate (Obach et al., 2004), and the positive controls, hydralazine and raloxifene (Obach, 2004), yielded the expected results in experiments involving recombinant AOX1 or tissue cytosols (Supplemental Fig. 6, A-C).

Comparative experiments showed that the decrease in carbazeran 4-oxidation by gefitinib was the greatest in enzymatic incubations containing human liver cytosol, lesser in incubations containing rat liver cytosol, and the least in incubations containing mouse liver cytosol, whereas the extent of the decrease by erlotinib in carbazeran 4 oxidation was similar in incubations containing each of these types of cytosols (Supplemental Fig. 6, B, D, and E). By comparison, the rank order of the decrease in carbazeran 4-oxidation by raloxifene was human liver cytosol $>$ mouse liver cytosol $>$ rat liver cytosol, whereas that by hydralazine was rat liver cytosol > mouse liver cytosol > human liver cytosol. Overall, these results suggest that the species differences in chemical inhibition of AOX catalytic activity are inhibitor-specific.

Enzyme Inhibition Kinetics and Mode of Inhibition of Human Liver Cytosolic AOX1 Catalytic Activity by Gefitinib, Erlotinib, and Select Metabolites. To determine the $K_{\mathrm{i}}$ and the mode of inhibition of carbazeran 4 oxidation by gefitinib, erlotinib, and select metabolites, liver cytosol was incubated with various concentrations of substrate and a test chemical. The $K_{\mathrm{i}}$ values were comparable between gefitinib and desmorpholinopropylgefitinib as well as among erlotinib, desmethylerlotinib, and didesmethylerlotinib (Table 1). As shown in Fig. 3 and summarized in Table 1, desmorpholinopropylgefitinib and erlotinib inhibited carbazeran 4-oxidation by partial competitive mode, whereas gefitinib, desmethylerlotinib, and didesmethylerlotinib inhibited it by full competitive mode.

Molecular Docking of Erlotinib and Select Metabolites to the Active Site of Human AOX1. Structural modeling of the orientation of erlotinib and select metabolites within the pocket (Fig. 4A) shows that erlotinib, desmethylerlotinib, and didesmethylerlotinib all bind in a broadly similar orientation. Didesmethylerlotinib forms a stronger interaction with AOX1 than erlotinib and desmethylerlotinib, as its unique hydroxyl group at the $\mathrm{C}_{6}$ position allows it to make an additional hydrogen bond with the thioether group in Met-889, increasing the stability of the ligand in the binding site. Desmethylerlotinib has a weaker interaction than erlotinib in binding to AOX1, as the preserved $\mathrm{C}_{7} \mathrm{O}$-methyl group is not able to form a hydrogen bond with Met-889, and the new hydroxyl group at $\mathrm{C}_{6}$ position diminishes its van der Waals compatibility with the edge of the pocket, forcing it to adopt an overall different and less energetically favorable configuration. Table 2 summarizes the 

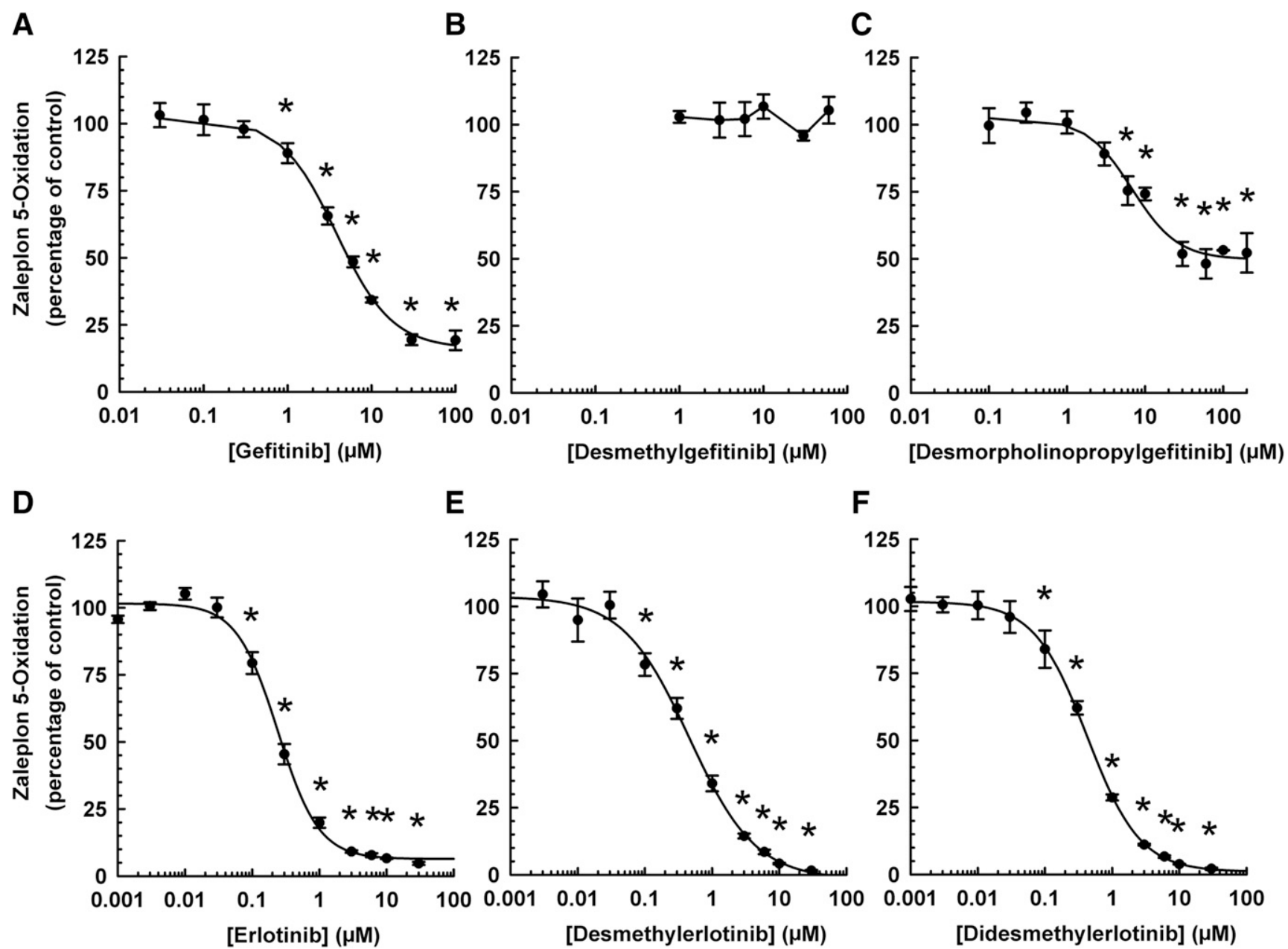

Fig. 6. Concentration-response relationship in the inhibitory effect of gefitinib, erlotinib, and select metabolites on zaleplon 5-oxidation catalyzed by human liver cytosol. Pooled liver cytosol $(60 \mu \mathrm{g}$ protein) was incubated with zaleplon $(80 \mu \mathrm{M})$ and varying concentrations of $(\mathrm{A})$ gefitinib $(0.03-100 \mu \mathrm{M})$, (B) desmethylgefitinib (1-60 $\mu \mathrm{M})$, (C) desmorpholinopropylgefitinib (0.1-200 $\mu \mathrm{M})$, (D) erlotinib (0.001-30 $\mu \mathrm{M})$, (E) desmethylerlotinib (0.003-30 $\mu \mathrm{M})$, (F) didesmethylerlotinib $(0.001-30 \mu \mathrm{M})$, or DMSO $\left(0.5 \% \mathrm{v} / \mathrm{v}\right.$; vehicle) at $37^{\circ} \mathrm{C}$ for 20 minutes. Data are expressed as percentage of activity in the vehicletreated control group and expressed as mean \pm S.E.M. of three or four independent experiments conducted in triplicate. *Significantly different from the vehicle-treated control group $(P<0.05)$.

key distances and interactions observed in the molecular docking of erlotinib and metabolites. There is a clear contrast with the predicted binding of hydralazine (Fig. 4B), which is indicated to be a relatively less potent inhibitor primarily because of the high activation energy cost of displacing the coordinated $\mathrm{OH}$ from the molybdenum cofactor and the small size of the ligand limiting the number of coordinating interactions it can make with surrounding residues.

Molecular Docking of Gefitinib and Select Metabolites to the Active Site of Human AOX1. The orientation and key ligand-residue interactions of gefitinib and select metabolites within the pocket support the role of gefitinib and desmorpholinopropylgefitinib (Fig. 4C) as reversible inhibitors. The poses generated for gefitinib (Fig. 5A) and desmorpholinopropylgefitinib (Fig. 5B) indicated key interactions with dioxothiomolybdenum (VI) ion (MOS), Phe-885, and Glu-888 (Table 2), which were previously implicated in our work on the reversible inhibition of this protein by selective estrogen receptor modulators (Chen et al., 2019). Structurally, gefitinib was able to form a stronger hydrogen bond with MOS because of its large morpholinopropyl side chain giving it a slightly different orientation in the pocket, whereas desmorpholinopropylgefitinib was better-coordinated by the surrounding phenylalanine residues.

Desmethylgefitinib had little or no inhibitory effect on AOX1-catalyzed carbazeran 4-oxidation, as determined in enzymatic incubations containing human recombinant AOX1 (Fig. 1B) or human liver cytosol (Fig. 1E). It appears that the different structure of the side chains in the desmethyl form (Supplemental Fig. 1) is responsible for its rejection from the pocket. A high-affinity conformation in the pocket entrance was observed in the desmethyl form (Fig. 5C) that was not observed in the other forms, in which Asn-1084 made two hydrogen bonds to two oxygen atoms attached to the main quinazoline ring that were inaccessible in the other forms of gefitinib. Although the halogenated ring binds in the correct subpocket, forming the same interactions with Phe-885 and Glu-888 (albeit notably weaker), it is the strong binding to Asn-1084 (Table 2) that ensures the central body of the ligand cannot coordinate with the cofactor in the molybdenum chamber of the pocket. Indeed, the bulk of the ligand binds obliquely to the outside of the broad pocket entrance in an orientation that suggests the ligand might easily be rejected from the vicinity of the pocket, not entering the pocket or 

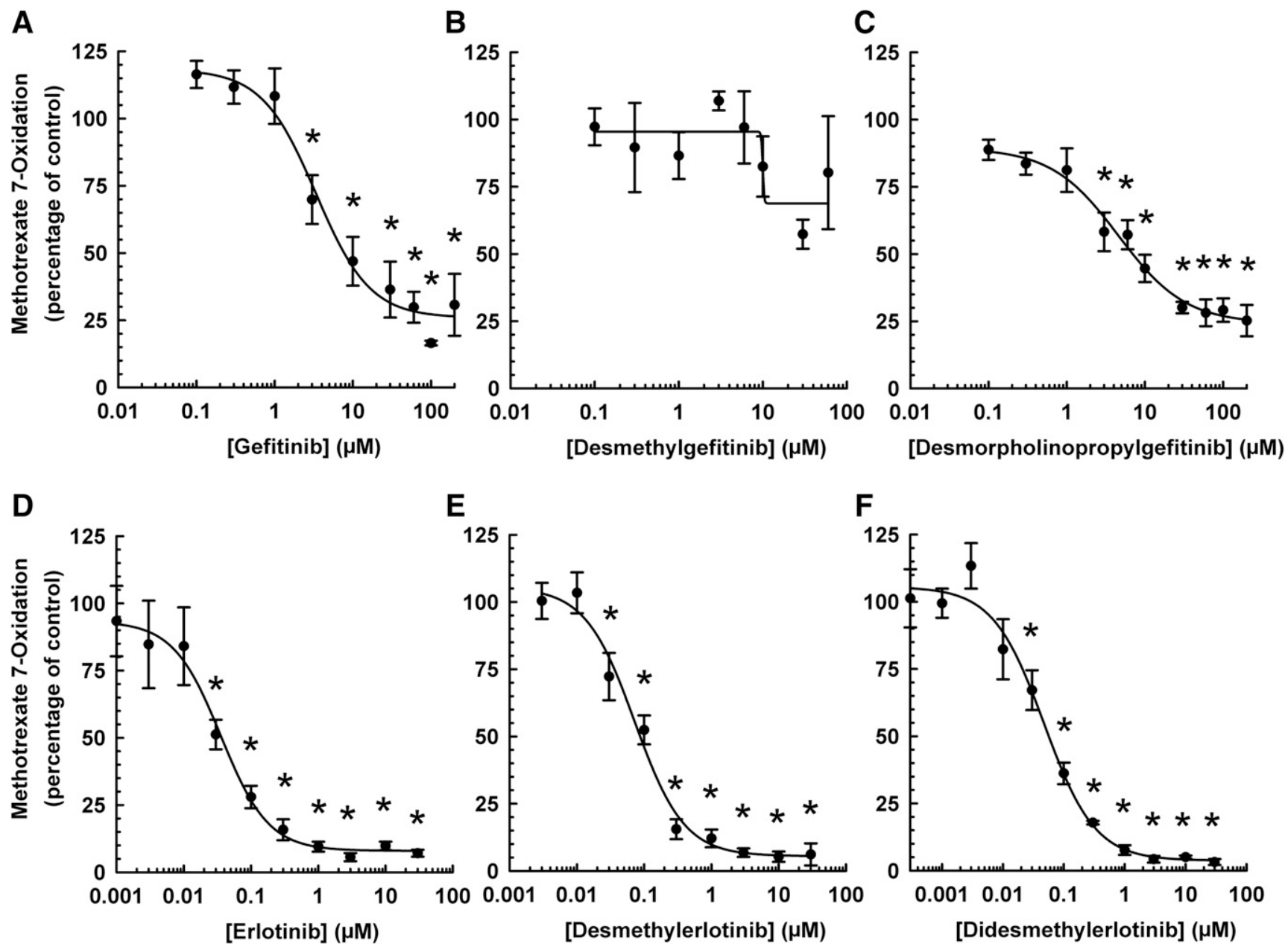

Fig. 7. Concentration-response relationship in the inhibitory effect of gefitinib, erlotinib, and select metabolites on methotrexate 7- oxidation catalyzed by human liver cytosol. Pooled liver cytosol (100 $\mu \mathrm{g}$ protein) was incubated with methotrexate (1.5 mM) and varying concentrations of (A) gefitinib $(0.1-200 \mu \mathrm{M})$, (B) desmethylgefitinib $(0.1-100 \mu \mathrm{M}),(\mathrm{C})$ desmorpholinopropylgefitinib $(0.1-200 \mu \mathrm{M})$, (D) erlotinib $(0.001-30 \mu \mathrm{M})$, (E) desmethylerlotinib $(0.003-30 \mu \mathrm{M}),(\mathrm{F})$ didesmethylerlotinib $(0.0003-30 \mu \mathrm{M})$, or DMSO $\left(0.5 \% \mathrm{v} / \mathrm{v}\right.$; vehicle) at $37^{\circ} \mathrm{C}$ for 180 minutes. Data are expressed as percentage of activity in the vehicle-treated control group and expressed as mean \pm S.E.M. of three or six independent experiments conducted in duplicate. *Significantly different from the vehicle-treated control group $(P<0.05)$.

interacting with the cofactor in the molybdenum chamber of the protein. As shown in Figs. 4D and 5C, bound desmethylgefitinib projects outwards from the pocket and does not appear to affect access to the molybdenum chamber for typical substrates of the enzyme, thereby not acting as an inhibitor.

Impact of AOX1 Inhibition by Gefitinib, Erlotinib, and Select Metabolites on Human Liver Cytosolic Metabolism of Zaleplon and Methotrexate. Our next research question was whether the inhibition of AOX1 by EGFR-TKIs impacts the metabolism of therapeutic drugs catalyzed predominantly by AOX1, such as zaleplon (Lake et al., 2002) and high-dose methotrexate (Jordan et al., 1999). Initial experiments were performed to validate the UPLC-MS/ MS methods for the quantification of 5-oxo-zaleplon and 7-oxomethotrexate (Supplemental Fig. 7; Supplemental Table 4), optimize the enzymatic conditions of the human liver cytosolic zaleplon 5-oxdation (Supplemental Figs. 3G, 4G, and 5G) and methotrexate 7-oxidation assays (Supplemental Figs. 3H, 4H, and $5 \mathrm{H}$ ), and characterize the kinetics of these enzymatic reactions (Supplemental Table 5). Enzyme inhibition experiments showed that gefitinib and desmorpholinopropylgefitinib, but not desmethylgefitinib, decreased zaleplon 5-oxidation (Fig. 6, A-C; Supplemental Fig. 8A) and methotrexate 7oxidation (Fig. 7, A-C; Supplemental Fig. 8B). In contrast, erlotinib, desmethylerlotinib, and didesmethylerlotinib efficaciously decreased zaleplon 5-oxidation (Fig. 6, D-F; Supplemental Fig. 8A) and methotrexate 7-oxidation (Fig. 7, D-F; Supplemental Fig. 8B), with a left shift in the respective concentration-response curves (Figs. 6, D-F and 7, D-F) when compared with the concentration-response curves for the inhibition of zaleplon 5-oxidation (Fig. 6, A and C) and methoxtrexate 7-oxidation (Fig. 7, A and C) by gefitinib and desmorpholinopropylgefitinib. The $\mathrm{IC}_{50}$ values were in the low micromolar concentrations for the inhibition of zaleplon 5-oxidation and methotrexate 7-oxidation by gefitinib and desmorpholinopropylgefitinib, whereas the $\mathrm{IC}_{50}$ values were in the nanomolar concentrations for the inhibition of these drug metabolism reactions by erlotinib, desmethylerlotinib, and didesmethylerlotinib (Supplemental Table 6). As expected, raloxifene and hydralazine (positive controls) decreased zaleplon 5-oxidation and methotrexate 7-oxidation, whereas sodium valproate (negative control) had no effect (Supplemental Fig. 8, A and B). 
A Gefitinib

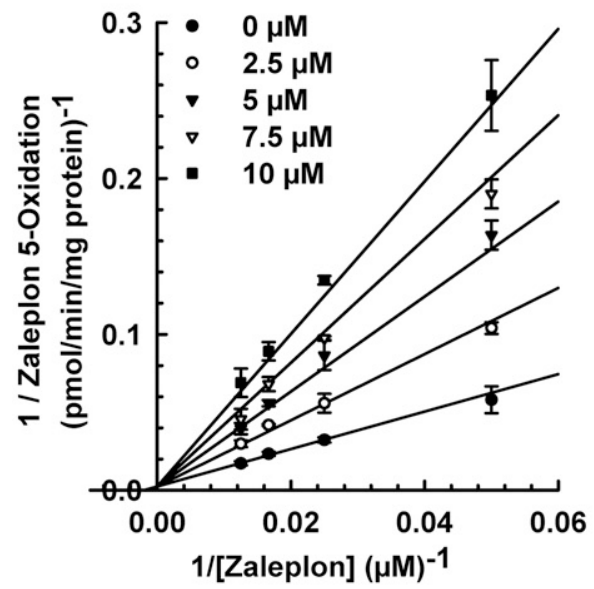

D Desmethylerlotinib

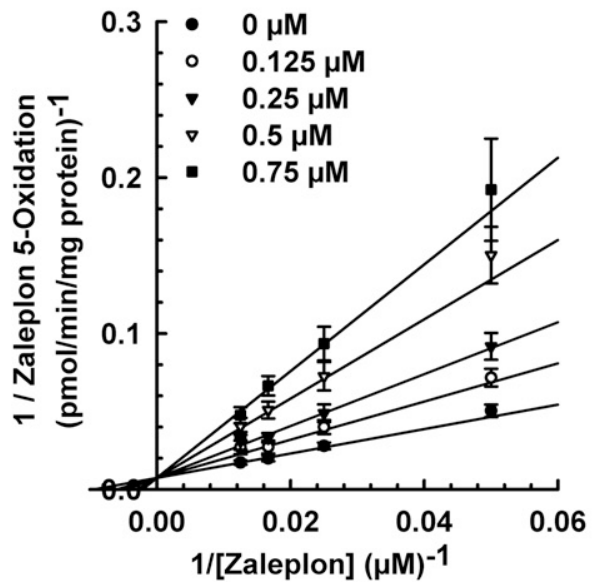

B Desmorpholinopropylgefitinib

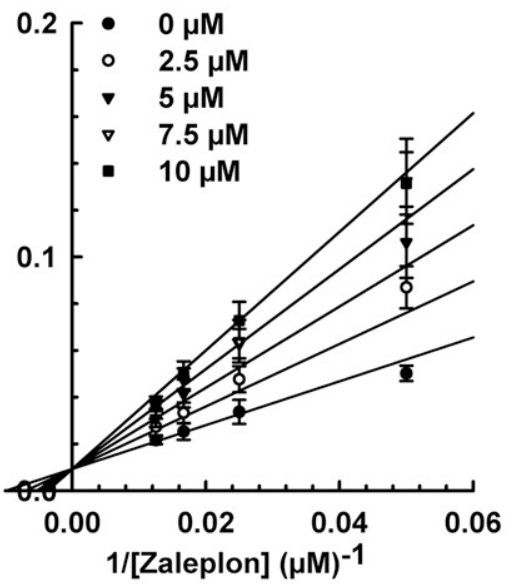

E Didesmethylerlotinib

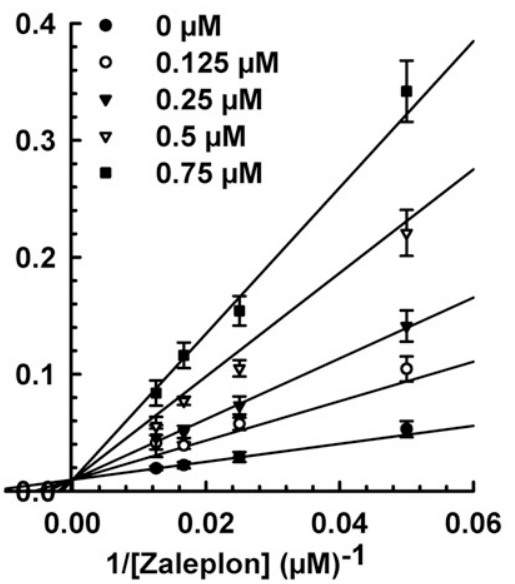

C Erlotinib

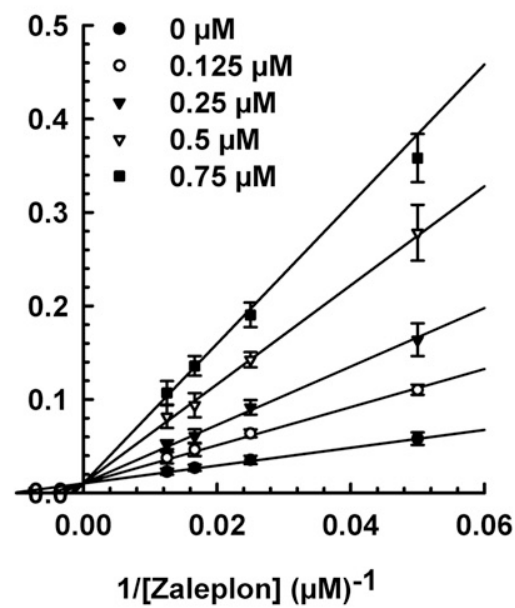

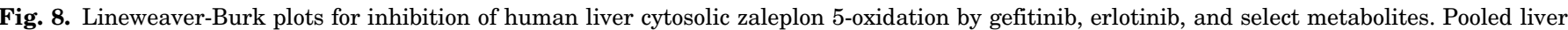

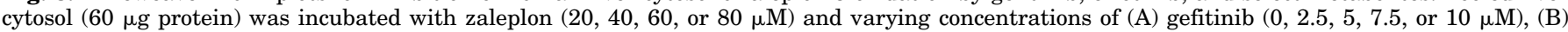

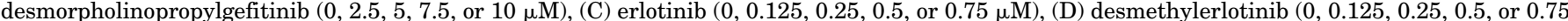

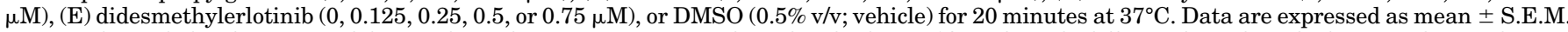

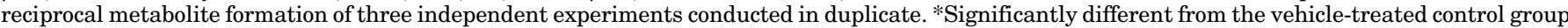
$(P<0.05)$.

Enzyme Inhibition Kinetics and Mode of Inhibition of Human Liver Cytosolic Zaleplon 5-Oxidation by Gefitinib, Erlotinib, and Select Metabolites. Additional experiments were performed to delineate the enzyme kinetics and mode of inhibition of zaleplon 5-oxidation by gefitinib, erlotinib, and select metabolites. As indicated in Table 1, the $K_{\mathrm{i}}$ values for the inhibition of liver cytosol-catalyzed zaleplon 5-oxidation by gefitinib and desmorpholinopropylgefitinib were greater than those by erlotinib, desmethylerlotinib, and didesmethylerlotinib by an order of magnitude. Nonlinear regression analysis and Lineweaver-Burk plots (Fig. 8) show that gefitinib, desmorpholinopropylgefitinib, erlotinib, desmethylerlotinib, and didesmethylerlotinib inhibited zaleplon 5oxidation by a competitive mode.

\section{Discussion}

As shown in our in vitro study, submicromolar concentrations of erlotinib and gefitinib are effective in inhibiting the catalytic activity of human AOX1. Possessing a quinazoline moiety, which is a common scaffold for good AOX1 substrates
(Lepri et al., 2017), gefitinib and erlotinib fit well into the AOX1 active site and support the competitive mode of AOX1 inhibition by these drugs. A comparison of the $K_{\mathrm{i}}$ values (Table 1) suggests that erlotinib is more potent than gefitinib in AOX1 inhibition. This could be due to the different substituents on the quinazoline and phenyl groups of these drugs (Supplemental Fig. 1). Erlotinib has an alkynyl group substituted on a benzene ring, whereas gefitinib has fluorine and chlorine groups substituted on a benzene ring. These structural differences may influence the interactions between the drug and the amino acid residues located near or at the binding site. As corroborated by molecular docking analysis, erlotinib binds through a hydrogen bond to the MOS group and interacts with Phe-923, whereas gefitinib also interacts through a hydrogen bond to the MOS group but forms a halogen bond with Glu-888 and interacts with Phe-885 (Table 2).

Erlotinib, desmethylerlotinib, and didesmethylerlotinib were shown to be potent competitive inhibitors of AOX, with submicromolar concentrations as their experimentally derived $K_{\mathrm{i}}$, or $\mathrm{IC}_{50}$ values. Among this group of chemicals, 
TABLE 3

Calculated $R_{1}$ values for the in vitro inhibitory effect of gefitinib, erlotinib, and select metabolites on human liver cytosolic carbazeran 4-oxidation and zaleplon 5-oxidation

Shown are unbound inhibition constant $\left(K_{\mathrm{i}, \mathrm{u}}\right)$ values, literature values of plasma protein binding, unbound maximum plasma drug concentrations ( $\left.\mathrm{I}_{\text {max }}\right)$, and calculated $\mathrm{R}_{1}$ values. Unbound $K_{\mathrm{i}, \mathrm{u}}$ data are expressed as mean \pm S.E.M.

\begin{tabular}{|c|c|c|c|c|c|c|c|}
\hline Chemical & $\begin{array}{c}\text { Carbazeran } \\
\text { 4-Oxidation } \\
K_{\mathrm{i}, \mathrm{u}}, \mu \mathrm{M}^{a}\end{array}$ & $\begin{array}{l}\text { Zaleplon } \\
\text { 5-Oxidation } \\
K_{\mathrm{i}, \mathrm{u}}, \mu \mathrm{M}^{a}\end{array}$ & Plasma $f_{u}$ & $\begin{array}{c}\text { Plasma Drug } \\
\text { Concentration } \\
\left(\mathrm{I}_{\max }\right), \mu \mathrm{M}\end{array}$ & $\begin{array}{l}\text { Unbound Plasma Drug } \\
\text { Concentration } \\
\left(\mathrm{I}_{\text {max }, \mathrm{u}}\right), \mu \mathrm{M}\end{array}$ & $\begin{array}{l}\text { Carbazeran } \\
\text { 4-Oxidation } \\
\mathrm{R}_{1} \text { Value }^{b}\end{array}$ & $\begin{array}{l}\text { Zaleplon } \\
\text { 5-Oxidation } \\
\mathrm{R}_{1} \text { Value }^{b}\end{array}$ \\
\hline Gefitinib & $1.23 \pm 0.28$ & $2.30 \pm 0.27$ & $0.10^{c}$ & $0.94-2.38^{d}$ & $0.094-0.238$ & $1.08-1.19$ & 1.04-1.10 \\
\hline Desmorpholinopropylgefitinib & $1.40 \pm 0.10$ & $6.74 \pm 1.70$ & Unknown & Unknown & n.d. & n.d. & n.d. \\
\hline Erlotinib & $0.23 \pm 0.02$ & $0.09 \pm 0.01$ & $0.07^{e}$ & $4.41-5.39^{f}$ & $0.31-0.38$ & $2.35-2.65$ & 4.44-5.22 \\
\hline Desmethylerlotinib & $0.45 \pm 0.04$ & $0.19 \pm 0.03$ & Unknown & $0.11-0.26^{g}$ & $0.0077-0.02$ & $1.02-1.04$ & $1.04-1.11$ \\
\hline Didesmethylerlotinib & $0.26 \pm 0.02$ & $0.10 \pm 0.01$ & Unknown & $0.002-0.011^{h}$ & $0.0001-0.0008$ & 1.00 & $1.00-1.01$ \\
\hline
\end{tabular}

n.d., not determined.

${ }^{a} K_{\mathrm{i}, \mathrm{u}}=\mathrm{f}_{\mathrm{u}} \times K_{\mathrm{i}}$, where $\mathrm{f}_{\mathrm{u}}$ was calculated from $10 \mu \mathrm{M}$ of chemicals in human liver cytosol (Supplemental Table 7).

${ }^{b} \mathrm{R}_{1}$ value $=1+\left[\mathrm{I}_{\mathrm{m}, \mathrm{u}}\right] / K_{\mathrm{i}, \mathrm{u}}$. According to the US Food and Drug Administration guidelines for in vitro drug interaction studies (Food and Drug Administration, 2020), a $\mathrm{R}_{1}$ value $\geq 1.02$ requires further investigations of potential in vivo inhibition. Shown in bold are $R_{1}$ values $\geq 1.02$.

${ }^{c}$ Gefitinib (IRESSA), package insert, 2018 (https://www.accessdata.fda.gov/drugsatfda_docs/label/2018/206995s $003 \mathrm{lbl}$.pdf).

${ }^{d}$ For advanced non-small cell lung cancer patients administered with $250 \mathrm{mg} /$ day of gefitinib, the $\mathrm{C}_{\max }$ was $418 \mathrm{ng} / \mathrm{ml}(0.94 \mu \mathrm{M})(\mathrm{Motonaga}$ et al., 2015$)$ or $662 \mathrm{ng} / \mathrm{ml}(1.48$ $\mu \mathrm{M}$ ) (on day 3) to $1064 \mathrm{ng} / \mathrm{ml}(2.38 \mu \mathrm{M}$ ) (on day 8) (Nakamura et al., 2010).

${ }^{e}$ Erlotinib (TARCEVA), package insert, 2016 (https://www.accessdata.fda.gov/drugsatfda_docs/label/2016/021743s025lbl.pdf). For desmethylerlotinib and didesmethylerlotinib, the $\mathrm{f}_{\mathrm{u}}$ is assumed to be similar to the parent drug.

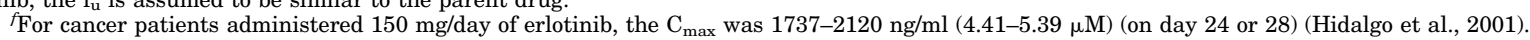

${ }^{g}$ For healthy nonsmoker volunteers administered a single $150 \mathrm{mg}$ dose of erlotinib, the $\mathrm{C}_{\max }$ was $43.5-98.3 \mathrm{ng} / \mathrm{ml}(0.11-0.26 \mu \mathrm{M})$ (Hamilton et al., 2006).

${ }^{h}$ For cancer patients administered $150 \mathrm{mg} /$ day of erlotinib for 1 to $2 \mathrm{mo}$, the $\mathrm{C}_{24} \mathrm{~h}$ was $0.86-4.2 \mathrm{ng} / \mathrm{ml}(2.35-11.49 \mathrm{nM})(\mathrm{Svedberg}$ et al., 2015).

erlotinib and didesmethylerlotinib were more potent than desmethylerlotinib. A comparison of their chemical structures (Supplemental Fig. 1) shows that the least potent AOX1 inhibitor in this group (i.e., desmethylerlotinib) has the terminal methyl group replaced by hydrogen on the $\mathrm{C}_{6}$ side chain of the quinazoline ring of the erlotinib scaffold. In the case of didesmethylerlotinib, the additional replacement of the terminal methyl group with hydrogen on the $\mathrm{C}_{7}$ side chain of the quinazoline ring appears to prevent the decrease in the potency of AOX1 inhibition. Our molecular docking analysis supports the relative potencies of erlotinib and its metabolites. Erlotinib forms a shorter stronger hydrogen bond with the MOS group (3.71 $\AA$ ) than either desmethylerlotinib (3.79 $\AA$ ) or didesmethylerlotinib (3.88 $\AA$ ), although the binding effects of the weaker MOS hydrogen bond for didesmethylerlotinib is likely to be compensated somewhat by an additional hydrogen bond with Met-889 (3.05 ̊).

Gefitinib and desmorpholinopropylgefitinib, but not desmethylgefitinib, inhibited AOX1 catalytic activity. The experimental findings on these structurally related chemicals suggest that 1 ) the methyl group at the $C_{7}$ side chain of the quinazoline ring of gefitinib is critical for inhibitor binding to the AOX1 active site; 2) alternatively, the acidic phenol group exposed from the loss of the $\mathrm{C}_{7}$ methyl group (in desmethylgefitinib) may hinder binding to the AOX1 active site; 3) indirectly, the $\mathrm{C}_{7}$ substituent could also alter the quinazoline propensity to interact with AOX1, as studies have shown that electronic effects (electron withdrawing/donating) of substituents have large effects on the quinazoline ring and impacts on substrate-enzyme binding (Lepri et al., 2017); and 4) the morpholinopropyl side chain, along with its basic nitrogen, at the $\mathrm{C}_{6}$ position of the ring is not essential for the inhibitory activity of gefitinib. Molecular docking analysis indicated similar key interactions between gefitinib and human AOX1 and between desmorpholinopropylgefitinib and this enzyme, consistent with the experimental findings that that these chemicals have efficacy as inhibitors of this enzyme.

Zaleplon, a nonbenzodiazepine sedative-hypnotic, is metabolized primarily by AOX1 and partly by CYP3A (Lake et al., 2002). In a human study, cimetidine, an inhibitor of AOX1
(Renwick et al., 2002) and CYP3A4 (Martinez et al., 1999), was reported to increase the $\mathrm{C}_{\max }$ and AUC of zaleplon by $83 \%$ and $85 \%$, respectively (Renwick et al., 2002). Given that gefitinib and erlotinib are far more potent AOX1 inhibitors (submicromolar to low micromolar $K_{\mathrm{i}}$, present study) than cimetidine $\left(K_{\mathrm{i}}\right.$ of $155 \mu \mathrm{M}$ ) (Renwick et al., 2002) and that erlotinib is also a dual inhibitor of AOX1 (present study) and CYP3A4 (Dong et al., 2011), a potential drug-drug interaction between gefitinib/erlotinib and zaleplon may occur. The US Food and Drug Administration guidance on in vitro drug interaction studies has a model to assess the risk of in vivo drug-drug interactions. It involves the calculation of $R_{1}$, which is equal to $1+\mathrm{I}_{\max , \mathrm{u}} / K_{\mathrm{i}, \mathrm{u}}$, where $\mathrm{I}_{\max , \mathrm{u}}$ is the maximal unbound plasma drug concentration (Table 3), and $K_{\mathrm{i}, \mathrm{u}}$ is the product of $K_{\mathrm{i}}$ and the fraction unbound (Supplemental Table 7). A $R_{1}$ value $\geq 1.02$ represents a risk for in vivo inhibition and potential drug-drug interactions (Food and Drug Administration, 2020). Based on the calculated $R_{1}$ values (Table 3 ), further investigations are warranted to determine whether erlotinib and gefitinib inhibit the in vivo metabolism of zaleplon. This is relevant because sleep disorder in cancer patients is prevalent, affecting about half of lung cancer patients undergoing chemotherapy (Mercadante et al., 2015), and a drug such as zaleplon may be used to treat insomnia in cancer patients administered erlotinib or gefitinib.

As shown in the present study, submicromolar concentrations of erlotinib, desmethylerlotinib, and didesmethylerlotinib inhibited human liver cytosolic methotrexate 7-oxidation. Methotrexate is an antifolate drug used in the treatment of various diseases (Widemann and Adamson, 2006). It is oxidized by AOX1 into its less active metabolite, 7-oxomethotrexate (also known as 7-hydroxymethotrexate) (Jacobs et al., 1976) (Supplemental Fig. 2). Both methotrexate and 7hydroxymethotrexate may precipitate in renal tubules when methotrexate is administered at high dosages $\left(>500 \mathrm{mg} / \mathrm{m}^{2}\right)$, contributing to the development of renal toxicity (Widemann and Adamson, 2006). Although the $R_{1}$ value for the interaction between erlotinib and methotrexate could not be determined because of the high substrate concentration $(1.5 \mathrm{mM})$ needed in the methotrexate 7-oxidation assay, the reported maximum 
plasma concentration of methotrexate is in the millimolar range in high-dose methotrexate therapy used for certain cancers (e.g., acute lymphoblastic leukemia, lymphomas, osteosarcomas) (Howard et al., 2016). Overall, the inhibitory effect by submicromolar concentrations of erlotinib, desmethylerlotinib, and didesmethylerlotinib (Fig. 7, D-F) would serve as the impetus for future investigations to determine whether erlotinib influences the in vivo metabolism and toxicity of methotrexate in human patients. As reported in a clinical study, a triple metronomic chemotherapy consisting of methotrexate, erlotinib, and celecoxib is efficacious for the treatment of refractory/advanced oral cancer (Patil et al., 2019).

Our study indicates differences in the magnitude of the inhibitory effect of gefitinib and desmorpholinopropylgefitinib on carbazeran 4-oxidation catalyzed by human, rat, and mouse liver cytosol (largest decrease in incubations containing human liver cytosol, smallest decrease in incubations containing mouse liver cytosol). In contrast, the magnitude of the inhibitory effect of erlotinib, desmethylerlotinib, and didesmethylerlotinib on carbazeran 4-oxidation was the same, regardless of whether the source of enzyme was human, rat, or mouse liver cytosol. In agreement with previous findings (Sahi et al., 2008; Apenova et al., 2018), species differences in chemical inhibition of AOX1 catalytic activity were also obtained with raloxifene and hydralazine, which were included as positive controls in our experiments. The reason for species-dependent chemical inhibition of AOX catalytic activity is unknown, but differences in size, shape, and amino acid residues in the active site of AOX1 have been postulated to affect binding by substrates (Dalvie and Di, 2019) and presumably also affects binding by competitive inhibitors.

In conclusion, gefitinib, erlotinib, and select metabolites, except for desmethylgefitinib, were shown to be potent competitive inhibitors of AOX1 catalytic activity. Nanomolar concentrations of erlotinib, desmethylerlotinib, and didesmethylerlotinib were sufficient to inhibit the hepatic cytosolic metabolism of zaleplon and methotrexate. Our molecular docking analyses provide structural insights into the key AOX1 interactions with erlotinib, desmethylerlotinib, didesmethylerlotinib, gefitinib, desmethylgefitinib, and desmorpholinopropylgefitinib. Furthermore, the emergence of a framework that systematically identifies key residues, bonds, and other interactions and their energies, and therein allows comparison and ranking of potential inhibitors, provides an opportunity for integration of strategies for the rational design and development of new EGFRTKIs for therapeutic purposes.

\section{Authorship Contributions}

Participated in research design: W. K. Tan, A. R. Y. Tan, Sivanandam, Goh, Yap, Saburulla, Lau.

Conducted experiments: W. K. Tan, A. R. Y. Tan, Sivanandam, Goh, Yap, Saburulla, Austin-Muttitt, Lau.

Performed data analysis: W. K. Tan, A. R. Y. Tan, Sivanandam, Goh, Yap, Saburulla, Austin-Muttitt, Mullins, Lau.

Wrote or contributed to the writing of the manuscript: Lau, AustinMuttitt, Mullins.

\section{References}

Apenova N, Peng H, Hecker M, and Brinkmann M (2018) A rapid and sensitive fluorometric method for determination of aldehyde oxidase activity. Toxicol Appl Pharmacol 341:30-37.
Behera D, Pattem R, and Gudi G (2014) Effect of commonly used organic solvents on aldehyde oxidase-mediated vanillin, phthalazine and methotrexate oxidation in human, rat and mouse liver subcellular fractions. Xenobiotica 44 $722-733$.

Chan BA and Hughes BG (2015) Targeted therapy for non-small cell lung cancer: current standards and the promise of the future. Transl Lung Cancer Res 4: $36-54$.

Chen S, Austin-Muttitt K, Zhang LH, Mullins JGL, and Lau AJ (2019) In vitro and in silico analyses of the inhibition of human aldehyde oxidase by bazedoxifene, lasofoxifene, and structural analogues. J Pharmacol Exp Ther 371:75-86.

Dalvie D and Di L (2019) Aldehyde oxidase and its role as a drug metabolizing enzyme. Pharmacol Ther 201:137-180.

Dong PP, Fang ZZ, Zhang YY, Ge GB, Mao YX, Zhu LL, Qu YQ, Li W, Wang LM, Liu CX, et al. (2011) Substrate-dependent modulation of the catalytic activity of CYP3A by erlotinib. Acta Pharmacol Sin 32:399-407.

Food and Drug Administration (2020) In vitro drug interaction studies - cytochrome P450 enzyme- and transporter-mediated drug interactions: guidance for industry. U.S. Department of Health and Human Services, Food and Drug Administration, Center for Drug Evaluation and Research (CDER), https://www.fda.gov/media/ 134582/download.

Hamilton M, Wolf JL, Rusk J, Beard SE, Clark GM, Witt K, and Cagnoni PJ (2006) Effects of smoking on the pharmacokinetics of erlotinib. Clin Cancer Res 12: $2166-2171$

Hidalgo M, Siu LL, Nemunaitis J, Rizzo J, Hammond LA, Takimoto C, Eckhardt SG, Tolcher A, Britten CD, Denis L, et al. (2001) Phase I and pharmacologic study of OSI-774, an epidermal growth factor receptor tyrosine kinase inhibitor, in patients with advanced solid malignancies. J Clin Oncol 19:3267-3279.

Howard SC, McCormick J, Pui CH, Buddington RK, and Harvey RD (2016) Preventing and managing toxicities of high-dose methotrexate. Oncologist 21: $1471-1482$

Jacobs SA, Stoller RG, Chabner BA, and Johns DG (1976) 7-Hydroxymethotrexate as a urinary metabolite in human subjects and rhesus monkeys receiving high dose methotrexate. J Clin Invest 57:534-538.

Jordan CG, Rashidi MR, Laljee H, Clarke SE, Brown JE, and Beedham C (1999) Aldehyde oxidase-catalysed oxidation of methotrexate in the liver of Guinea-pig, rabbit and man. J Pharm Pharmacol 51:411-418.

Kujtan L and Subramanian J (2019) Epidermal growth factor receptor tyrosine kinase inhibitors for the treatment of non-small cell lung cancer. Expert Rev Anticancer Ther 19:547-559.

Kundu TK, Velayutham M, and Zweier JL (2012) Aldehyde oxidase functions as a superoxide generating NADH oxidase: an important redox regulated pathway of cellular oxygen radical formation. Biochemistry 51:2930-2939.

Lake BG, Ball SE, Kao J, Renwick AB, Price RJ, and Scatina JA (2002) Metabolism of zaleplon by human liver: evidence for involvement of aldehyde oxidase. Xenobiotica 32:835-847.

Lepri S, Ceccarelli M, Milani N, Tortorella S, Cucco A, Valeri A, Goracci L, Brink A, and Cruciani G (2017) Structure-metabolism relationships in human-AOX: chemical insights from a large database of aza-aromatic and amide compounds. Proc Natl Acad Sci USA 114:E3178-E3187.

Li J, Zhao M, He P, Hidalgo M, and Baker SD (2007) Differential metabolism of gefitinib and erlotinib by human cytochrome P450 enzymes. Clin Cancer Res 13: 3731-3737.

Ling J, Johnson KA, Miao Z, Rakhit A, Pantze MP, Hamilton M, Lum BL, and Prakash C (2006) Metabolism and excretion of erlotinib, a small molecule inhibitor of epidermal growth factor receptor tyrosine kinase, in healthy male volunteers. Drug Metab Dispos 34:420-426.

Manevski N, Balavenkatraman KK, Bertschi B, Swart P, Walles M, Camenisch G, Schiller H, Kretz O, Ling B, Wettstein R, et al. (2014) Aldehyde oxidase activity in fresh human skin. Drug Metab Dispos 42:2049-2057.

Martínez C, Albet C, Agúndez JA, Herrero E, Carrillo JA, Márquez M, Benítez J, and Ortiz JA (1999) Comparative in vitro and in vivo inhibition of cytochrome P450 CYP1A2, CYP2D6, and CYP3A by H2-receptor antagonists. Clin Pharmacol Ther 65:369-376.

McKillop D, McCormick AD, Miles GS, Phillips PJ, Pickup KJ, Bushby N, and Hutchison M (2004) In vitro metabolism of gefitinib in human liver microsomes. Xenobiotica 34:983-1000.

Mercadante S, Aielli F, Adile C, Ferrera P, Valle A, Cartoni C, Pizzuto M, Caruselli A, Parsi R, Cortegiani A, et al. (2015) Sleep disturbances in patients with advanced cancer in different palliative care settings. J Pain Symptom Manage 50:786-792.

Moriwaki Y, Yamamoto T, Takahashi S, Tsutsumi Z, and Hada T (2001) Widespread cellular distribution of aldehyde oxidase in human tissues found by immunohistochemistry staining. Histol Histopathol 16:745-753.

Motonaga M, Yamamoto N, Makino Y, Ando-Makihara R, Ohe Y, Takano M, and Hayashi Y (2015) Phase I dose-finding and pharmacokinetic study of docetaxel and gefitinib in patients with advanced or metastatic non-small-cell lung cancer: evaluation of drug-drug interaction. Cancer Chemother Pharmacol 76:713-721.

Nakamura Y, Sano K, Soda H, Takatani H, Fukuda M, Nagashima S, Hayashi T, Oka M, Tsukamoto K, and Kohno S (2010) Pharmacokinetics of gefitinib predicts antitumor activity for advanced non-small cell lung cancer. J Thorac Oncol 5: 1404-1409.

Nishimura M and Naito S (2006) Tissue-specific mRNA expression profiles of human phase I metabolizing enzymes except for cytochrome P450 and phase II metabolizing enzymes. Drug Metab Pharmacokinet 21:357-374.

Obach RS (2004) Potent inhibition of human liver aldehyde oxidase by raloxifene. Drug Metab Dispos 32:89-97.

Obach RS, Huynh P, Allen MC, and Beedham C (2004) Human liver aldehyde oxidase: inhibition by 239 drugs. J Clin Pharmacol 44:7-19.

Okamoto Ken, Kawaguchi Yuko, Eger Bryan T, Pai Emil F, and Nishino Takesh (2010) Crystal structures of urate bound form of xanthine oxidoreductase: substrate orientation and structure of the key reaction intermediate. $J$ Am Chem Soc 132 (48):17080-17083, doi: 10.1021/ja1077574 21077683. 
Otteneder MB, Knutson CG, Daniels JS, Hashim M, Crews BC, Remmel RP, Wang H, Rizzo C, and Marnett LJ (2006) In vivo oxidative metabolism of a major peroxidation-derived DNA adduct, $\mathrm{M}_{1 \mathrm{dG}}$. Proc Natl Acad Sci USA 103 6665-6669.

Patil VM, Noronha V, Joshi A, Dhumal S, Mahimkar M, Bhattacharjee A, Gota V, Pandey M, Menon N, Mahajan A, et al. (2019) Phase I/II study of palliative triple metronomic chemotherapy in platinum-refractory/early-failure oral cancer. $J$ Clin Oncol 37:3032-3041.

Qiao Y, Maiti K, Sultana Z, Fu L, and Smith R (2020) Inhibition of vertebrate aldehyde oxidase as a therapeutic treatment for cancer, obesity, aging and amyotrophic lateral sclerosis. Eur J Med Chem 187:111948.

Renwick AB, Ball SE, Tredger JM, Price RJ, Walters DG, Kao J, Scatina JA and Lake BG (2002) Inhibition of zaleplon metabolism by cimetidine in the human liver: in vitro studies with subcellular fractions and precision-cut liver slices. Xenobiotica 32:849-862.

Sahi J, Khan KK, and Black CB (2008) Aldehyde oxidase activity and inhibition in hepatocytes and cytosolic fractions from mouse, rat, monkey and human. Drug Metab Lett 2:176-183.

Stanulović M and Chaykin S (1971) Aldehyde oxidase: catalysis of the oxidation of $\mathrm{N}^{1}$-methylnicotinamide and pyridoxal. Arch Biochem Biophys 145:27-34.
Svedberg A, Gréen H, Vikström A, Lundeberg J, and Vikingsson S (2015) A validated liquid chromatography tandem mass spectrometry method for quantification of erlotinib, OSI-420 and didesmethyl erlotinib and semi-quantification of erlotinib metabolites in human plasma. J Pharm Biomed Anal 107:186-195.

Tomita S, Tsujita M, and Ichikawa Y (1993) Retinal oxidase is identical to aldehyde oxidase. FEBS Lett 336:272-274.

Wauchope OR, Beavers WN, Galligan JJ, Mitchener MM, Kingsley PJ, and Marnett LJ (2015) Nuclear oxidation of a major peroxidation DNA adduct, $\mathrm{M}_{1} \mathrm{dG}$, in the genome. Chem Res Toxicol 28:2334-2342.

Widemann BC and Adamson PC (2006) Understanding and managing methotrexate nephrotoxicity. Oncologist 11:694-703.

Xie J, Saburulla NF, Chen S, Wong SY, Yap ZP, Zhang LH, and Lau AJ (2019) Evaluation of carbazeran 4-oxidation and $O^{6}$-benzylguanine 8-oxidation as catalytic markers of human aldehyde oxidase: impact of cytosolic contamination of liver microsomes. Drug Metab Dispos 47:26-37.

Address correspondence to: Dr. Aik Jiang Lau, Department of Pharmacy, Faculty of Science, National University of Singapore, 18 Science Drive 4 Singapore 117543, Singapore. E-mail: aikjiang.lau@nus.edu.sg 